\title{
Lignin depolymerization: a comparison of methods to analyze monomers and oligomers
}

Erika Bartolomeia, Yann Le Brecha, Anthony Dufoura*, Vincent Carre ${ }^{b}$, Frederic Aubriet ${ }^{b}$, Evan Terrellc, Manuel Garcia-Perezc ${ }^{c}$ Philippe Arnouxa*

${ }^{a}$ LRGP, CNRS, Université de Lorraine, 1 rue Grandville, 54000 Nancy, France

b LCP-A2MC,Université de Lorraine, 1 Boulevard Arago, F-57078, Metz, France

c Department of Biological Systems Engineering, Washington State University, Pullman, WA 99164, USA

* corresponding author: anthony.dufour@univ-lorraine.fr, philippe.arnoux@univ-lorraine.fr

\begin{abstract}
Catalytic liquefaction of lignin is an attractive process for the production of fuels and chemicals, but it forms a wide range of liquid products from monomers to oligomers. Oligomers represent an important fraction of the products and their analysis is complex. Therefore, rapid characterization methods are needed in order to screen liquefaction conditions based on the distribution in monomers and oligomers. For this purpose, we propose UV spectroscopy as a fast and simple method to assess the composition of lignin-derived liquids. UV absorption and fluorescence were studied on various model compounds and liquefaction products. Liquefaction of Soda lignin was conducted in an autoclave, in ethanol and with $\mathrm{Pt} / \mathrm{C}$ catalyst $\left(\mathrm{H}_{2}, 250^{\circ} \mathrm{C}, 110\right.$ bar). Liquids were sampled at isothermal conditions every 30 minutes for 4 hours. UV fluorescence spectroscopy is related to GC/MS, GPC, MALDI-TOFMS and NMR characterizations. A depolymerization index is proposed from UV spectroscopy in order to rapidly assess the relative distribution of monomers and oligomers.
\end{abstract}




\section{Table of contents (only for review)}

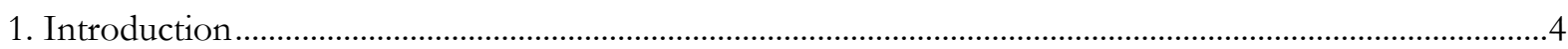

2. Material and methods ............................................................................................................................6

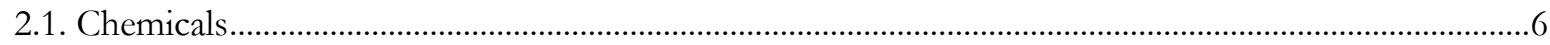

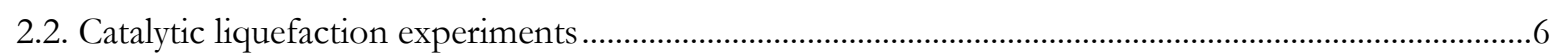

2.3. Analysis of products ........................................................................................................................

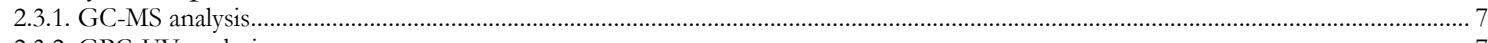

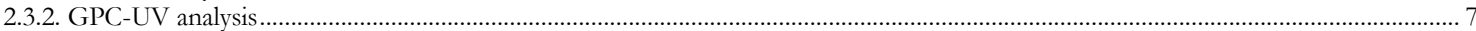

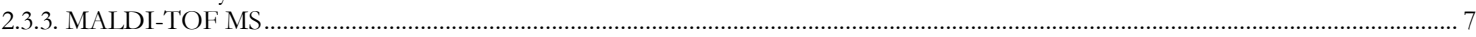

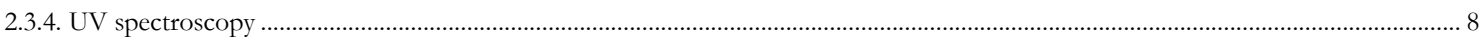

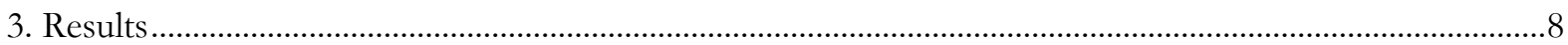

3.1. Analysis of lignin liquefaction products by conventional methods ................................................

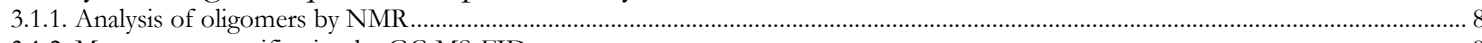

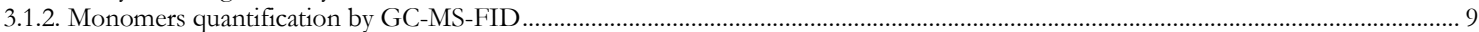

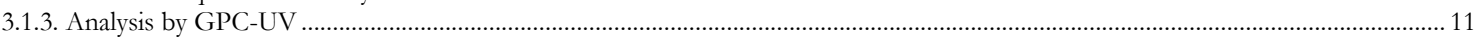

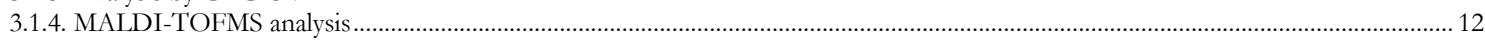

3.2. Analysis of lignin products by UV spectroscopy ................................................................. 14

3.2.1. UV spectroscopy of model compounds, lignin and isolated oligomers ........................................................................................... 14

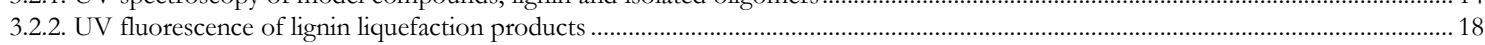

4. Discussion on the complementarity between UV fluorescence and GC/MS, MALDI-TOFMS and GPC

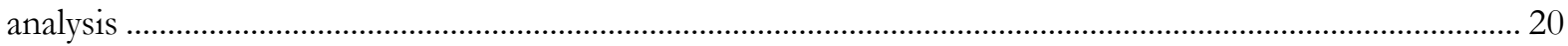

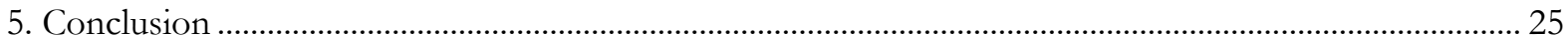

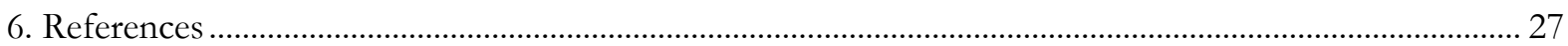

\section{List of figures (only for review)}

Figure 1. Yield (wt. lignin based) for the principal products after 4 hours of reaction, with and without catalyst.

Figure 2. Monomers mass yields (based on lignin mass) by GC/MS-FID as a function of the time of reaction.

Figure 3. Mw and Mn of lignin oils from GPC analysis, with and without catalyst, as a function of reaction time

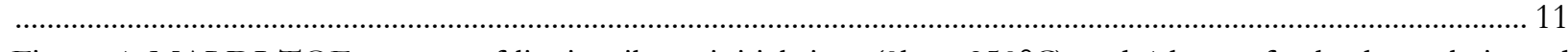

Figure 4. MALDI-TOF spectra of lignin oils, at initial time $\left(0 \mathrm{~h}\right.$ at $\left.250^{\circ} \mathrm{C}\right)$ and 4 hours for both catalytic and non-catalytic reactions $(*$ is at $\mathrm{m} / \mathrm{z} 273$, the peak of DHB matrix) ................................................................ 12

Figure 5. Integration of the signal of ions detected by MALDI-TOFMS in lignin oils from 0 to $240 \mathrm{Da}$ and 240 to $1800 \mathrm{Da}$ as a function of reaction time, without and with catalyst .................................................................. 13

Figure 6. Molecular weight distribution ( $\mathrm{Mw}$ and $\mathrm{Mn}$ ) of lignin oils obtained by MALDI-TOFMS as a function of time on stream $\left(\right.$ at $\left.250^{\circ} \mathrm{C}\right)$, with and without catalyst (Pt/C).

Figure 7. Synchronous UV fluorescence with $20 \mathrm{~nm}$ offset of model compounds, lignin and oligomers (diluted in ethanol)

Figure 8. Emission peak maxima in synchronous excitation fluorescence (20 nm offset) for model compounds, oligomers and lignin, diluted in ethanol...

Figure 9. Synchronous Fluorescence (offset $20 \mathrm{~nm}$ ) for different reaction time: a) without catalyst b) synchronous fluorescence with catalyst.

Figure 10. Depolymerization index (DI) and monomeric products index (MPI) obtained by UV fluorescence analysis as a function of liquefaction time $\left(\right.$ at $\left.250^{\circ} \mathrm{C}\right)$, without and with catalyst $(\mathrm{Pt} / \mathrm{C})$.

Figure 11. Simplified representation of lignin products in solution and of the analytical methods assessed in this work.

Figure 12. Comparison between the MALDI analysis (integration of all detected ions from $\mathrm{m} / \mathrm{z} 0$ to 1800 ) and the depolymerization index (DI) derived from UV fluorescence for the 8 lignin oils (without and with catalyst, 4 samples upon liquefaction time)

Figure 13. Comparison between low MW species detected by MALDI ( $\mathrm{m} / \mathrm{z} 0-240)$, products quantified by GC/MS (up to 240Da) and the monomers index (MPI) derived from UV fluorescence.

Figure 14. Simplified representation of lignin depolymerization in ethanol based on the complementary methods employed in this work. 


\section{Introduction}

Lignin is the main renewable resource of aromatic compounds ${ }^{[1]}$. The native lignin present in biomass is a threedimensional amorphous macromolecule made up principally by the combination of three different phenylpropane monomer units: p-coumaryl alcohol $(\mathrm{H})$, guaiacyl alcohol $(\mathrm{G})$ and syringyl alcohol $(\mathrm{S})$, linked mainly by aryl ether bonds ( $\beta-\mathrm{O}-4)$ in a randomized way ${ }^{[2-9]}$. Lignin is an abundant aromatic feedstock, but it is still largely considered as a source for heat and power for bio-refinery or pulping processes ${ }^{[1,3,10-12]}$. The lack of well-established processes that add value to lignin can be largely attributed to its structural complexity and associated chemical recalcitrance ${ }^{[8,13-15]}$.

The use of lignin as a feedstock for the production of bio-based chemicals has received increasing interest ${ }^{116-}$ 21]. The development of efficient processes for lignin valorization presents an important potential to improve the economic feasibility and overall sustainability of both pulp and paper processing and cellulosic-based ethanol biorefineries ${ }^{[1,22,23]}$.

Lignin conversion to value-added products is chiefly governed by an interplay of three technological biorefinery aspects: (i) lignocellulosic biomass fractionation, (ii) lignin depolymerization, and (iii) upgrading towards targeted (intermediate or final) chemicals, such as through hydrotreatment. ${ }^{[24]}$

Efficient lignin depolymerization could produce a wide range of fuels and chemicals (and/or their precursors). $[1,2,17,24,25]$ Numerous studies have been carried out on lignin depolymerization to obtain phenolic compounds in an oil fraction (lignin-oil)[16,24-28]. These molecules (especially alkylated phenol like guaiacol) could be used to produce chemicals and materials (polymers, antioxidants, resins, medicines, or pesticides) in substitution to fossil fuel resources ${ }^{[24,29]}$.

Lignin reductive depolymerization is often performed in the presence of a reduced metallic catalyst on various supports (e.g., $\mathrm{Ru} / \mathrm{Al}_{2} \mathrm{O}_{3}, \mathrm{Ru} / \mathrm{C}, \mathrm{Ru} / \mathrm{TiO}_{2}, \mathrm{Pd} / \mathrm{C}, \mathrm{Pt} / \mathrm{C}$ ) ${ }^{[30-35]}$, a reducing agent (which is mainly hydrogen) and a solvent. The mechanisms of lignin depolymerization have been reviewed recently. ${ }^{[36,37]}$

Molecular hydrogen can be brought directly as a gas $\left(\mathrm{H}_{2}\right)$, solubilized in the solvent, and/or it can be derived from organic H-donors, such as alcohols (like ethanol) or even from the lignin matrix itself. Hydrogen transfer from organic $\mathrm{H}$-donors is an attractive alternative to using high-pressure $\mathrm{H}_{2}$, which presents important safety and handling issues. ${ }^{[38]}$

For this reason, reductive depolymerization of lignin with alcohol is a promising process to produce phenolic compounds ${ }^{[30-34]}$. Supercritical alcohols are effective for lignin depolymerization because of their unique physical-chemical properties, namely: (i) high heat transfer, (ii) high solubilisation capability, and (iii) hydrogen donor behavior ${ }^{[30-33,33,34]}$. Ethanol is an interesting solvent for lignin liquefaction because it is a cheap solvent which could be produced in the biorefinery from cellulose. Furthermore, ethanol is considered as formaldehyde scavenger to prevent the repolymerization of lignin decomposition products. ${ }^{[32]}$ Ethanol can react with lignin side-chains to prevent the condensation reaction between lignin fragments ${ }^{[39]}$.

Among all tested catalysts, $\mathrm{Pt} / \mathrm{C}$ has been shown as one of the most effective catalysts for lignin depolymerization processes, producing large yields of lignin-oil $(77.4 \mathrm{wt} \%)$ with a small amount of char (3.7 $\mathrm{wt} \%$ ); there is also high selectivity for monomeric phenols. ${ }^{[30]}$

For all these reasons, we have selected $\mathrm{Pt} / \mathrm{C}$ and ethanol as liquefaction conditions for the present study.

Reductive liquefaction is generally operated at about $300^{\circ} \mathrm{C}$ and $100 \mathrm{bar}$. It forms various monomers that are mainly p-substituted methoxyphenols[27,30,40-43]. Lignin catalytic depolymerization in supercritical ethanol can lead to a yield between 5 and $20 \%$ wt of monomers from initial lignin ${ }^{[3,33,34,44]}$.

Nevertheless, there is still an important yield of non-monomeric compounds remaining after treatment (i.e. oligomers, condensed insoluble fractions, solid char). For instance, high molecular-weight phenolic compound 
("oligomers") yields have been obtained in the range of 35 to $65 \%$ (wt.) with methanol, ethanol and propanol used as solvent in the presence of different catalysts. ${ }^{[30]}$

Therefore, it is of tremendous importance to develop analytical approaches in order to assess the mass yield and composition in oligomers as a function of operating conditions.

Various methods have been reported in literature in order to analyze oligomers from lignin depolymerization. Acid precipitation followed by solvent extraction and evaporation has been proposed ${ }^{[33]}$ to isolate oligomers from the solvent. It is a valuable method to quantify the mass yield of oligomers; however, it is time consuming and requires a significant amount of toxic solvent (like THF).

Gel permeation chromatography (GPC) is a common method for analyzing the molecular weight of macromolecules. It has been extensively studied on lignin and liquefaction products. ${ }^{[4-48]}$ But a careful calibration must be achieved due to potential chemical interactions between lignin molecules and the column. ${ }^{[49]}$ The different structure (hydrodynamic volume) between lignin products and calibration standards also impairs the quality of the molar masses determined by GPC. ${ }^{[50]}$

Laser desorption ionization mass spectrometry (LDI-MS) as well as other ionization techniques has been used on lignin and its products ${ }^{[51-55]}$ for "lignomic" studies. ${ }^{[56,57]}$ Computational and graphical methods are currently used to elucidate the composition of oligomers. ${ }^{[57,58]}$ LDI has been combined with high resolution mass spectrometry (HRMS) to analyze lignin and wood bio-oil[59,60], biochar[61] and on lignin pyrolysis intermediates. ${ }^{[4]}$ Matrix assisted LDI (MALDI) combined with time of flight mass spectrometry (TOFMS) has been used on lignin liquefaction products.[21,62,63] This method gives the distribution of main $\mathrm{m} / \mathrm{z}$ values from monomeric and oligomeric species present in the bio-oil. A tentative description of oligomeric structure is derived from MALDI MS analysis, but other HRMS techniques (i.e., FT-ICR MS) are more recommended, in comparison to TOFMS, for elucidating the chemical composition of lignin oligomers. ${ }^{57,58]}$

UV-visible (UV-Vis) spectroscopy has been used to quantify soluble lignini[64,65]. Chen et al. have monitored lignin electrochemical depolymerization using UV spectroscopy ${ }^{[6]]}$. UV-Vis is sensitive to aromatic species, and the solubilized lignin can be characterized by the evolution of specific electronic transitions ${ }^{[6]}$. UV fluorescence spectroscopy (UV-FS) can also be used to study aromatic molecules [68]. Both UV-Vis and UV-FS are nondestructive, fast and do not require large sample amounts[ ${ }^{[0]}$.

Among UV fluorescence methods, synchronous fluorescence spectroscopy has been extensively used to study complex aromatic mixtures from coal[68-72], asphaltenes ${ }^{[73,74]}$ and biomass pyrolysis ${ }^{[67,75-78]}$. In synchronous fluorescence, excitation and emission wavelengths vary simultaneously separated by a constant offset. The obtained spectrum depends on both fluorophore absorption and emission. Synchronous fluorescence spectroscopy has been demonstrated as a powerful method to analyze the molecular size of the conjugated compounds present in a complex mixture. ${ }^{[69,70,74,79,80]}$ Despite numerous studies on lignin UV spectroscopy, synchronous UV fluorescence has not yet been proposed for lignin liquefaction products.

To date, this approach has not yet been rationalized and compared with other techniques for lignin liquid analysis.

It is of tremendous importance to combine analytical methods in order to obtain a more complete assessment of the complex liquids produced from lignin.

UV-FS has been compared to HPLC on coal liquids by Katoh et al. [70] This early work has demonstrated the usefulness of synchronous fluorescence spectroscopy on coal-derived liquids, despite the limitation of the method in which some molecules give only weak peaks. GPC, HPLC and UV-fluorescence have been compared in detail by Delpuech et al.[79] on coal hydroliquefaction and pyrolysis liquids. SEC, LDI-MS and fluorescence have been compared on coal tar pitch. ${ }^{[69]}$ Some inconsistency may occur with LDI-MS notably 
due mass discrimination effects. ${ }^{[81]}$ These studies on coal liquids are an important source of information which can be extended and adapted for lignin liquids.

SEC, MALDI-TOFMS and LDI-MS (among other methods) have been compared by Meier et al.[82] on different pyrolytic lignins produced from wood pyrolysis. SEC was the only method that allowed a mathematical calculation of molar mass characteristics. LDI-MS gave the molar mass of oligomer subunits.

All these studies highlight potential inconsistencies between methods used to analyse heavy liquid products.

For this reason, the goal of this study is to compare the methods for analyzing the liquids from lignin liquefaction. To the best of our knowledge, we propose for the first time the use of synchronous UV fluorescence spectroscopy as a fast screening method to assess oligomers/monomers relative distribution from lignin liquefaction. A lignin "depolymerization index" is proposed based on UV spectroscopy. The UV results are discussed with complementary analysis, namely NMR, GPC, MALDI-TOF-MS and GC/FID-MS. The pitfalls and benefits associated to each method for analyzing lignin-derived liquids are discussed.

\section{Material and methods}

\subsection{Chemicals}

The lignin used for liquefaction experiments was a Protobind 1000, produced by soda pulping of wheat straw and marketed by GreenValue ${ }^{\circledR}$.

Elemental analysis showed the following composition (wt. \%): C, 62.9 ( \pm 0.09$)$; H, $5.8( \pm 0.01)$; O, $29.5( \pm 0.01)$; N $0.4( \pm 0) ; S, 0.7( \pm 0.1)$; ash content 1.73 ( \pm 0.37$)$; dry mass $95.6( \pm 0.6)$. Relative Mn (number average molecular weight) and $\mathrm{Mw}$ (weight average molecular weight) were respectively 1525 and $3650 \mathrm{~g} / \mathrm{mol}$ (similar as Constant ${ }^{[8]}$, based on PS standards, THF GPC method after acetylation). This GPC method may under-estimate lignin molecular weight. [50]

The catalyst used was Platinum on carbon (5\% wt., Pt/C) from Sigma Aldrich (ref.205931). The references of model compounds are given in supplementary material.

\subsection{Catalytic liquefaction experiments}

Lignin liquefaction was carried out in a $300 \mathrm{~mL}$ autoclave purchased from Parr Instruments (4890 series, see Supplementary Material). The reactor was loaded with $9.56 \mathrm{~g}$ of lignin (dry basis), $200 \mathrm{~mL}$ of pure ethanol as solvent and $\mathrm{Pt} / \mathrm{C}$ solid catalyst to reach 1\% wt. Pt on lignin, mass basis $(2.0 \mathrm{~g}$ of $\mathrm{Pt} / \mathrm{C}$ catalyst, $5 \% \mathrm{wt}$. of $\mathrm{Pt}$ loading on catalyst mass basis).

An internal standard (100 $\mu$ l, hexadecane, Sigma Aldrich ref 52209) was injected in the autoclave (with $200 \mathrm{~mL}$ ethanol, lignin and catalyst) before the start of the reaction. Hexadecane has been checked to be not reactive under the reaction conditions. This internal calibration allows a more accurate quantification of monomers present in the sampled solutions by GC/MS-FID.

After loading and sealing, the reactor was purged 5 times with $\mathrm{N}_{2}$ in order to remove the air and charged with $\mathrm{H}_{2}\left(10 \mathrm{bar}\right.$, MESSER $\left.\mathrm{H}_{2}>99.9 \%\right)$ to set a reductive atmosphere. The autoclave was heated by the following temperature program: start temperature $=20^{\circ} \mathrm{C}$, heating rate $=5 \mathrm{~K} \mathrm{~min}^{-1}$, final temperature $=250^{\circ} \mathrm{C}, 4 \mathrm{~h}$ at $250^{\circ} \mathrm{C}$, cooling time of about $35 \mathrm{~min}$ to room temperature (cooling by a high flow rate of compressed air flushing the outer the surface of the reactor). In this work, time " 0 " is defined once the temperature reached $250^{\circ} \mathrm{C}$ (first sampling). The magnetic stirrer was maintained at $400 \mathrm{rpm}$ during the reaction.

The liquid was sampled under isothermal condition $\left(\right.$ at $250^{\circ} \mathrm{C}$ ) by a sampling device including high pressure valves and a fixed sampling volume (of $3 \mathrm{~mL}$ ). The sampling line was purged 2 times before the sample was collected in order to avoid contaminations between different samples. The sampled volume is small compared 
to the initial $200 \mathrm{~mL}$ of solution and it does not impact the overall reaction conditions (checked by experiments without sampling).

All the samples were analyzed by different analytical techniques without any further manipulation (such as solvent extraction).

Oligomers and solid residue obtained at the end of the reaction (after cooling of the autoclave) were also isolated (see supplementary material).

\subsection{Analysis of products}

\subsubsection{GC-MS analysis}

The samples were analyzed by an Agilent 7890 gas chromatograph combined to an Agilent 5975C MS (operated by electron impact at $70 \mathrm{eV}$ ) and an FID placed in parallel to the mass spectrometer. The samples were filtered ( $0.45 \mu \mathrm{m}$ glass filters) and no additional dilution was applied. The sample was injected $(1 \mu \mathrm{L})$ with a split ratio of 10 into an Agilent HP-5MS (5\% phenyl 95\% methyl siloxane) column. The oven was maintained at $50^{\circ} \mathrm{C}$ for $10 \mathrm{~min}$; then the temperature was increased with a first ramp of $5^{\circ} \mathrm{C} / \mathrm{min}$ to $120^{\circ} \mathrm{C}$, maintained for $10 \mathrm{~min}$ and then with a second ramp of $5^{\circ} \mathrm{C} / \mathrm{min}$ to $250^{\circ} \mathrm{C}$ and maintained for $18 \mathrm{~min}$. By comparison between the mass spectra and the NIST database, more than 40 compounds have been identified. The quantification was achieved by the FID detector based on the de Saint Laumer ${ }^{[83]}$ method as previously described in detail[59]. This method is able to predict the relative response factor of a compound on a FID based on its combustion enthalpy.

\subsubsection{GPC-UV analysis}

The molecular weight distribution of lignin liquefaction products was determined by GPC using a Shimadzu Prominence HPLC system.

Acetylation was used on Soda lignin but not on the liquefaction products because it was complex to control the acetylation in the presence of ethanol. The samples, in ethanol from the reaction, were filtered $(0.45 \mu \mathrm{m}$ glass filters) and then diluted in THF (by 1:4 v/v), the same solvent of the mobile phase. $20 \mu \mathrm{L}$ was injected. The stationary phase was composed of: 1) a Phenomenex Phenogel $5 \mu \mathrm{m}(7.8 \times 50 \mathrm{~mm})$ guard column, 2) a Shodex GPC KF-806L $10 \mu \mathrm{m}(8.0 \times 300 \mathrm{~mm})$ analytical column and 3) a Phenomenex Phenogel $5 \mu \mathrm{m} 100 \AA$ $(7.8 \times 300 \mathrm{~mm})$. The samples were separated at $35^{\circ} \mathrm{C}$ with a flow rate of $1 \mathrm{~mL} / \mathrm{min}$. The standards used for calibration were polystyrenes. We are aware that polystyrenes and lignin products present different hydrodynamic volumes for a same molecular weight but PS standards were used for sake of comparison with the available literature on lignin liquefaction ${ }^{[31,34,82,84]}$. The absorbance of the eluted products is presented at 254 nm (Shimadzu SPD-20A). Data were collected and analyzed with LabSolutions software.

\subsubsection{MALDI-TOF MS}

Lignin and liquefaction products (in ethanol) were analyzed by matrix-assisted laser desorption/ionization (MALDI) time of flight (TOF) mass spectrometry (MS) (Bruker Ultraflex II, $355 \mathrm{~nm} \mathrm{Nd:YAG} \mathrm{laser,} 60 \mu \mathrm{m}$ spot diameter, $\sim 10^{7} \mathrm{~W} \mathrm{~cm}^{-2}$ at $50 \%$ power). The method was established according to previously published protocols [85]. For calibration of the mass spectrometer, the polyethylene glycol (PEG 600) mixed with 2,5dihydroxy benzoic acid (2,5 DHB) matrix was used. A saturated 2,5 DHB solution $\left(30 \mathrm{mg} \mathrm{mL}^{-1}\right.$ in methanol/water 50/50) was added to the different lignin-derived solutions (sampled directly from the autoclave, in ethanol, see supplementary materials for more details).

After homogenization of the solution, it was deposited dropwise $(\sim 10 \mu \mathrm{L})$ onto the instrument sample holder in distinct spots. Deposit of collected samples but without DHB matrix were also analyzed for comparison. 2,5 
DHB was shown to be needed in order to reduce fragmentation and aggregation [56,58,82,85]. Only the MALDI results are presented in this paper. The reported mass spectra were obtained in positive ion detection mode and are the sum of 1000 individual mass spectra (200 shots on 5 different locations on the same spot).

The effect of laser energy has been studied as well as the effect of lignin concentration in DHB. Only ions in the 0 to $1800 \mathrm{~m} / \mathrm{z}$ range were detected.

\subsubsection{UV spectroscopy}

UV-visible absorption spectra were recorded on a UV-3600 double beam spectrophotometer (Shimadzu, Marne la Vallée, France). A spectral range from $200 \mathrm{~nm}$ to $500 \mathrm{~nm}$ and scan speed of $100 \mathrm{~nm} \mathrm{~min}{ }^{-1}$ were selected with lamp change at $340 \mathrm{~nm}$. The fluorescence spectra were recorded on a Fluorolog FL3-222 spectrofluorometer (HORIBA Jobin Yvon, Longjumeau, France) equipped with a $450 \mathrm{~W}$ Xenon lamp, and a UV-Visible photomultiplier R928 (HAMAMATSU Japan). All spectra were measured in a four-faced quartz cell. Fluorescence spectra were obtained with right angle detector position for both emission and synchronous acquisitions. Emission acquisition was performed with excitation wavelength of $275 \mathrm{~nm}$ and a slit of $2 \mathrm{~nm}$ for a spectral range of $280 \mathrm{~nm}$ to $530 \mathrm{~nm}$. Synchronous acquisition was performed with a constant wavelength offset of $20 \mathrm{~nm}$ in the spectral range from $250 \mathrm{~nm}$ to $500 \mathrm{~nm}$. The $20 \mathrm{~nm}$ offset has been selected based on previous work. ${ }^{69,79]}$

The samples were diluted in ethanol until the absorption wavelength at $275 \mathrm{~nm}$ was approximately 0.2 , in order to avoid self-absorption effects. ${ }^{[69,86]}$ For this purpose, the solutions sampled from lignin liquefaction (10g of lignin in $200 \mathrm{~mL}$ ethanol, $50 \mathrm{~g}$ lignin equivalent $/ \mathrm{L}$ ) were diluted 1000 or 2000 times in ethanol. Therefore, the concentration of analyzed solutions is in the range of $25-50 \mathrm{mg}$ lignin equivalent $/ \mathrm{L}$ ethanol for $\mathrm{UV}$ analysis.

All the synchronous fluorescence spectra are presented at the same absorbance.

The whole procedure (including dilution, scan acquisition and treatment of data) lasts only about 15 minutes.

\section{Results}

\subsection{Analysis of lignin liquefaction products by conventional methods}

\subsubsection{Analysis of oligomers by NMR}

Oligomers were isolated after the 4hour liquefaction of lignin and characterized by NMR (presented in supplementary Material). The method of oligomers fractionation from the ethanol solution is also presented in supplementary material.

NMR characterization of the oligomers demonstrates that conjugated ether bonds are even lower (not detected) than in Soda lignin. Similar findings were shown for pyrolytic lignin from wood pyrolysis. ${ }^{[87]}$ The "chemical severity" of 1) lignin extraction from biomass (by the Soda process) and 2) lignin liquefaction induces a complete conversion of ether bonds. Indeed, it is well known that lignin depolymerization induces a significant reduction in the number of the main ether linkages between lignin units: resinol structure $(\beta-\beta / \alpha-\mathrm{O}-\gamma)$, phenylcoumaran $(\beta-5 / \alpha-O-4)$ and $\beta-O-4$ structure. ${ }^{37,88,89]}$ The rupture of ether bonds leads to the formation of very reactive free phenolic hydroxyl groups (through radical or charged species) [33,37] and chains, unsaturated side chains, which both participate in condensation reactions ${ }^{37,90]}$. The condensation reactions are favored by the proximities of fragments/moieties within the rigid lignin frame. This repolymerization leads to a more condensed structure, described as a char-like structure with fused aromatic rings[ ${ }^{37,91]}$, by different chemical mechanisms: vinylcondensation, quinone methide, radical coupling[191,92]. The mass of char has been analyzed (see supplementary material). $\mathrm{Pt} / \mathrm{C}$ catalyst considerably reduces char formation compared to the experiment without catalyst in agreement with $\mathrm{Kim}$ et al.[30]. $\mathrm{Pt} / \mathrm{C}$ also reduces the mass yield in precipitated oligomers. Therefore, $\mathrm{Pt} / \mathrm{C}$ seems to inhibit some condensation reactions. 


\subsubsection{Monomers quantification by GC-MS-FID}

Chromatograms, reproducibility and a complete list of the monomeric products quantified by GC/MS-FID are presented in supplemental material. Figure 1 displays the total mass yield in monomers and the yield of some major selected species for liquefaction with and without catalyst (at the end of the liquefaction, after $4 \mathrm{~h}$ at $250^{\circ} \mathrm{C}$ ).

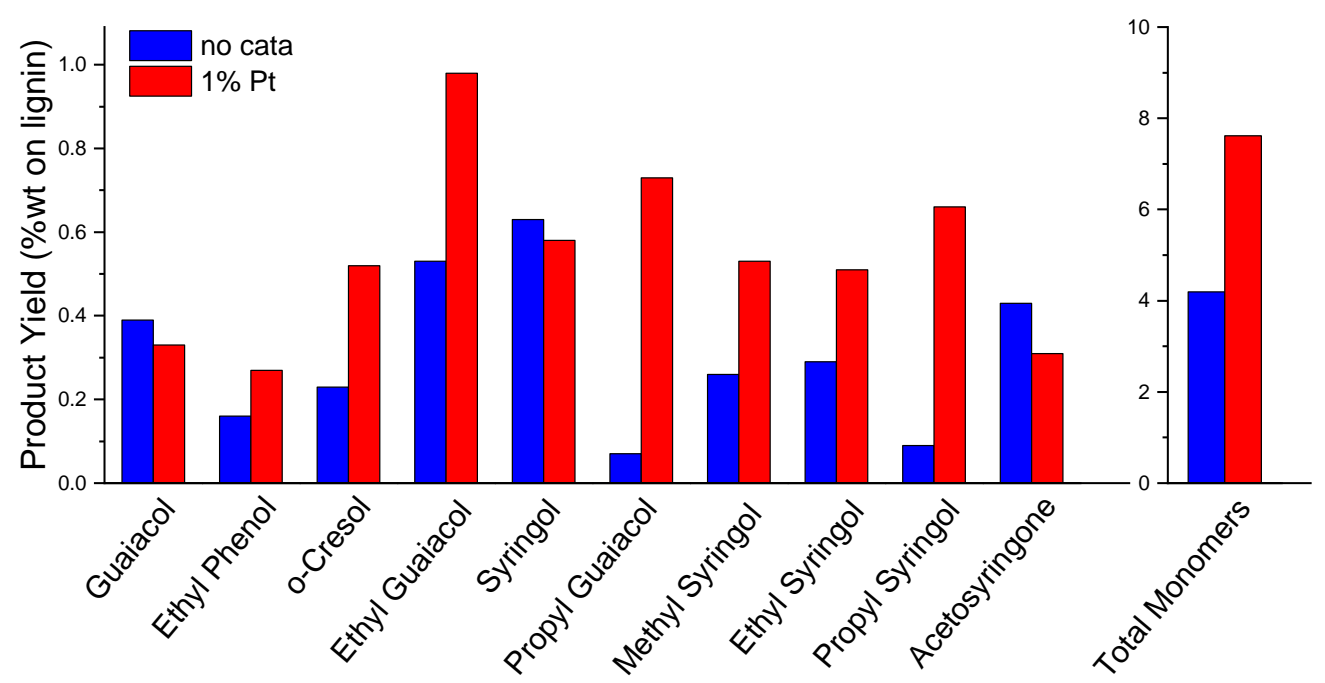

Figure 1. Yield (wt. lignin based) for the principal products after 4 hours of reaction, with and without catalyst.

The catalyst has a clear influence on the monomeric production. It doubles the total monomers (from 4 to $7.8 \mathrm{wt} \%$ ). To the best of our knowledge, Kim et al. has presented the closest conditions to ours (same lignin, ethanol, same catalyst, same load $20 \mathrm{wt} . \%) .{ }^{[30]}$ Their monomer mass yield $(8.1 \mathrm{wt} . \%)$ is very similar to our analysis despite a higher temperature and shorter residence time $\left(350^{\circ} \mathrm{C}-40 \mathrm{~min}, 250^{\circ} \mathrm{C}-4 \mathrm{~h}\right.$, in our case). Monomer yields could be further increased by a decrease in catalyst load and by optimization of liquefaction conditions (reduction secondary reactions). This is due to excessive catalyst load inducing unwanted side reactions.[30]

The major monomers are alkyl methoxy-phenols, in close agreement with Kim et al.[30]. Pt/C promotes considerably the formation of ethyl- and propyl- guaiacol, and methyl-, ethyl- and propyl- syringol. Kim et al. also noticed the same remarkable increase of alkylphenols with the catalyst (under their Pt-20\% condition).

Figure 2 presents the evolution of some selected monomers as a function of time for both catalyzed and not catalyzed conditions. 

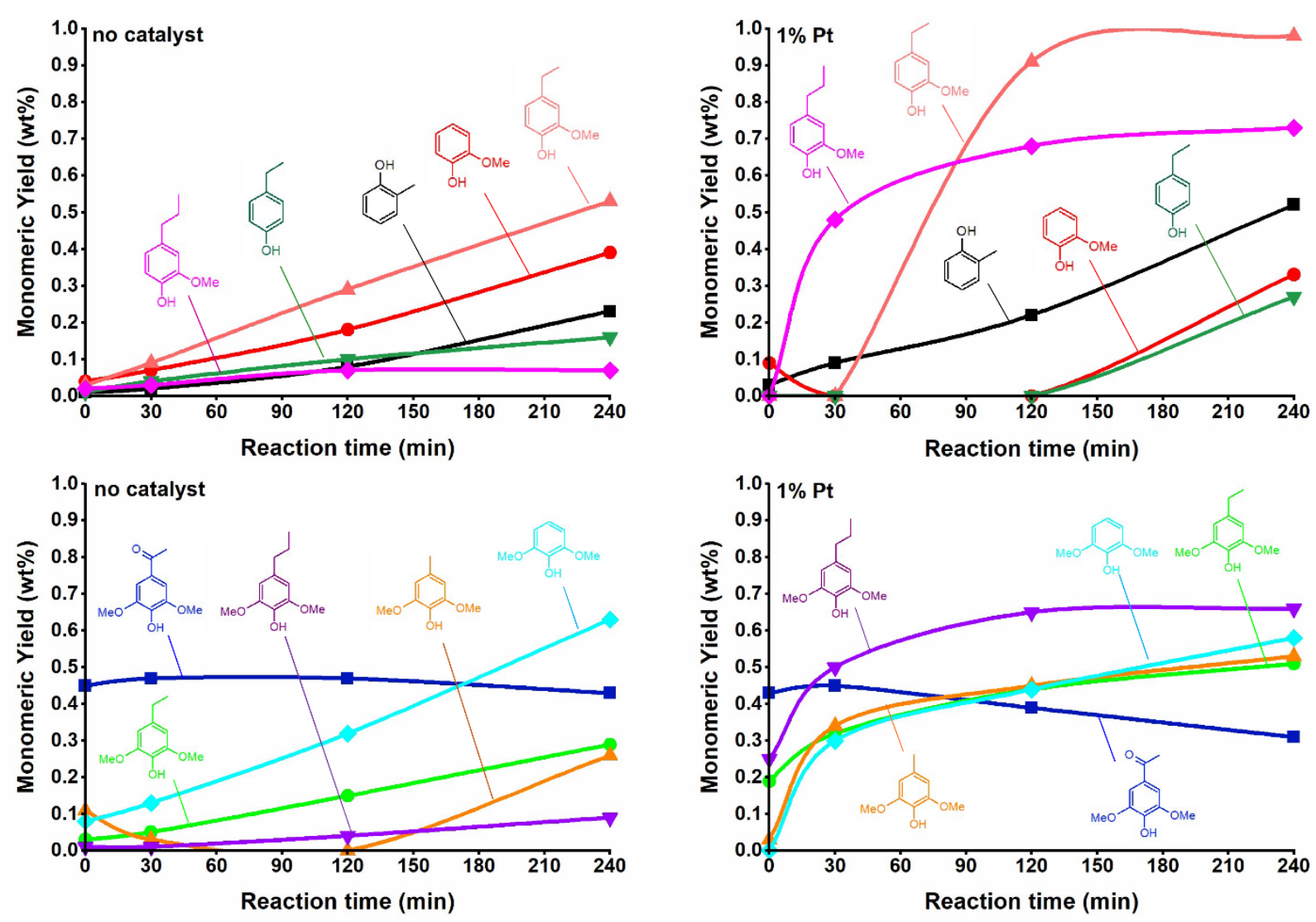

Figure 2. Monomers mass yields (based on lignin mass) by GC/MS-FID as a function of the time of reaction.

Without catalyst, the main monomers are progressively formed up to 4hours time on stream, except acetosyringone which is formed in the earlier step.

$\mathrm{Pt} / \mathrm{C}$ significantly promotes the yields and the formation rates of alkyl phenols, such as ethyl- and propylguaiacol and of methyl-, ethyl- and propyl- syringol. These compounds are formed much earlier in the first 30 minutes' time on stream (except ethyl guaiacol) compared to results without catalyst.

The NMR analysis of the isolated oligomers demonstrates a complete rupture of ether bonds in oligomers even without catalyst (only with ethanol). The oligomers may be formed from homogeneous conversion in supercritical ethanol with a poor participation of the heterogeneous catalyst. Indeed, the $\mathrm{Pt} / \mathrm{C}$ catalyst exhibits a high surface area of about $1100 \mathrm{~m}^{2} / \mathrm{g}$ (Pt/activated carbon) mainly due to micropores $(<2 \mathrm{~nm})$. ${ }^{30]}$ Lignin macromolecules are unlikely to be converted within these pores due to mass transfer limitations. The important yield in alkylphenols with the catalyst may be explained by a promotion of $\mathrm{C}-\mathrm{C}$ bond conversion in oligomers. Furthermore, $\mathrm{Pt} / \mathrm{C}$ exhibits a high surface area which promotes the adsorption/desorption of hydrogen atoms. ${ }^{[30]}$ Therefore, $\mathrm{Pt} / \mathrm{C}$ may also promote the transfer of $\mathrm{H}$ atoms to stabilize the broken $\mathrm{C}-\mathrm{C}$ bonds and form more stabilized monomers. This mechanism is consistent with a lower char and oligomer yields with $\mathrm{Pt} / \mathrm{C}$ (see supplementary material).

It is interesting to note that acetosyringone presents the same yield in the first $30 \mathrm{~min}$, with and without the catalyst. It may be formed by the early conversion of the few ether bonds present in Soda lignin. This finding is in excellent agreement with a study on model compounds under similar conditions. ${ }^{[93]}$ It has been shown that the cleavage of the $\beta$-O-4 linkage is fast $(<15 \mathrm{~min}$ ) and leads to the formation of acetophenone species (like acetosyringone in our case) through $\mathrm{H}$-transfer hydrogenolysis of an intermediate pentacyclic ether bond.[93] This similar feature of early acetosyringone formation with and without catalyst consolidates our discussion on the conversion of ether bonds without an important action of the catalyst (as supported by oligomers NMR 
analysis). Then, the conversion of acetosyringone is slightly promoted by the catalyst after $30 \mathrm{~min}$ time on stream.

Cresol, guaiacol and ethyl-phenol are mainly formed after 2 hours time on stream. They may be formed by secondary reactions (like partial dealkylation) of primary monomers. The presence of cresol exemplifies an interesting feature of this catalytic system (ethanol and $\mathrm{Pt} / \mathrm{C}$ ): the methylation of the aromatic ring. This reaction is of high interest in increasing the carbon balance in monomers.

Some carbohydrate-derived compounds were detected in small yields (see supporting material), possibly formed by the conversion of lignin-carbohydrate linkages or residual carbohydrates (as evidenced by our NMR analysis of lignin). At low reaction time some ethanol-derived products are detected (1-Butanol; 1,4-Dioxin,2,3-dihydro; 1,1-diethoxy-Ethane; Butanoic acid, ethyl ester; 1,1-diethoxy-Butane; 2,4,6-Cyclopentanone,2-ethyl; 2-ethylCyclopentanone; see supporting material for more details). In addition to monomeric phenols, low yields in esters and acids (like butanedioic acid, diethyl ester) are observed. They are probably the result of recondensation reactions between low molecular compounds with $\mathrm{C}-\mathrm{C}$ or $\mathrm{C}-\mathrm{O}$ bonds in lignin-oil, as shown in previous studies ${ }^{[84,94,95]}$.

\subsubsection{Analysis by GPC-UV}

The mass-average molecular weight $(\mathrm{Mw})$ of pristine lignin was $3600 \mathrm{Da}$ and the isolated oligomer fraction was $800 \mathrm{Da}$. We are aware that our GPC method may under-estimate the real molecular weight ${ }^{[50]}$ but it allows a more direct comparison with other works using the same GPC method. ${ }^{[30,82]}$ Lignin oils (compounds soluble in ethanol) were sampled at specified reaction times, then diluted in THF and analyzed by GPC (figure 3).

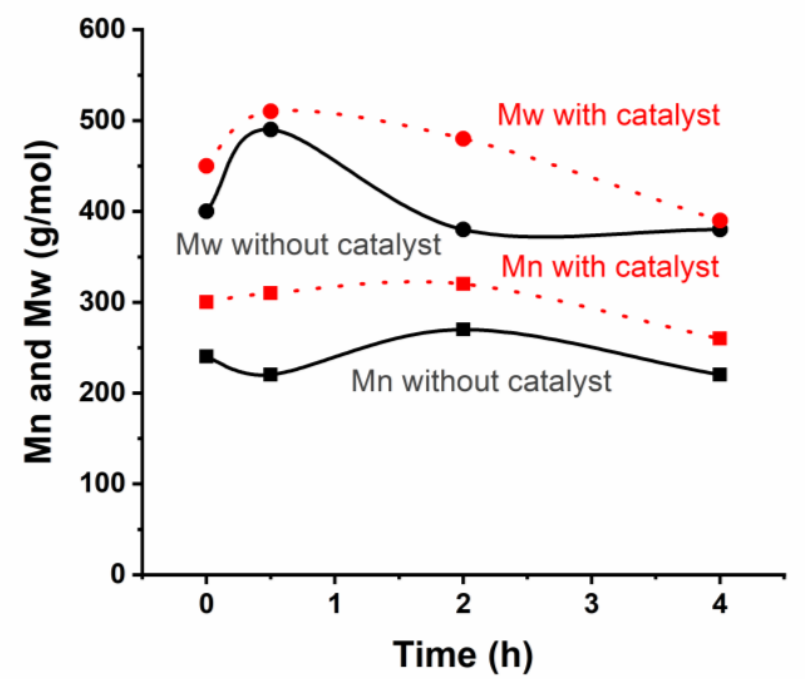

Figure 3. Mw and Mn of lignin oils from GPC analysis, with and without catalyst, as a function of reaction time

All GPC curves exhibit only one major peak with a unimodal distribution (see Supplementary Material). Our columns and calibration method were not tailored for a separation between monomers, dimers, tetramers, etc. The catalyzed and uncatalyzed experiments presents a similar evolution on $\mathrm{Mw}$ and $\mathrm{Mn}$ (figure 3) with relatively stable Mw and Mn. Mw and Mn are slightly higher for catalytic liquefaction.

The $\mathrm{Mw}$ and polydispersity index (PDI, Mw/Mn) of lignin oil found by Kim et al. ${ }^{[30]}$ were 595Da and 1.3 (with $20 \%$ wt. Pt/C). In our case (with catalyst), Mw is between 400 and $500 \mathrm{Da}$, with a constant PDI of 1.5.

The oligomers ( $\mathrm{Mw} \sim 800 \mathrm{Da}$ ) extracted by acid precipitation represent a heavy part of the GPC curve of ligninoil. 
Although $\mathrm{Mw}$ of lignin-oil is relatively stable across reaction sampling times, the monomer yields increase as analysed by GC/MS. This finding displays the concurrent depolymerization of the oligomeric pool (formation of monomers) and recondensation (formation of oligomers and char), as previously proposed by several authors. ${ }^{[30,33]}$

\subsubsection{MALDI-TOFMS analysis}

Figure 4 presents the MALDI-TOF mass spectra of two samples (without catalyst and with $\mathrm{Pt} / \mathrm{C}$ catalyst) at two reaction times ( 0 and 4 hours) for the same liquid samples (species soluble in ethanol) as the ones analyzed by GC/MS and GPC. MALDI ionization conditions have been optimized (see supporting material).
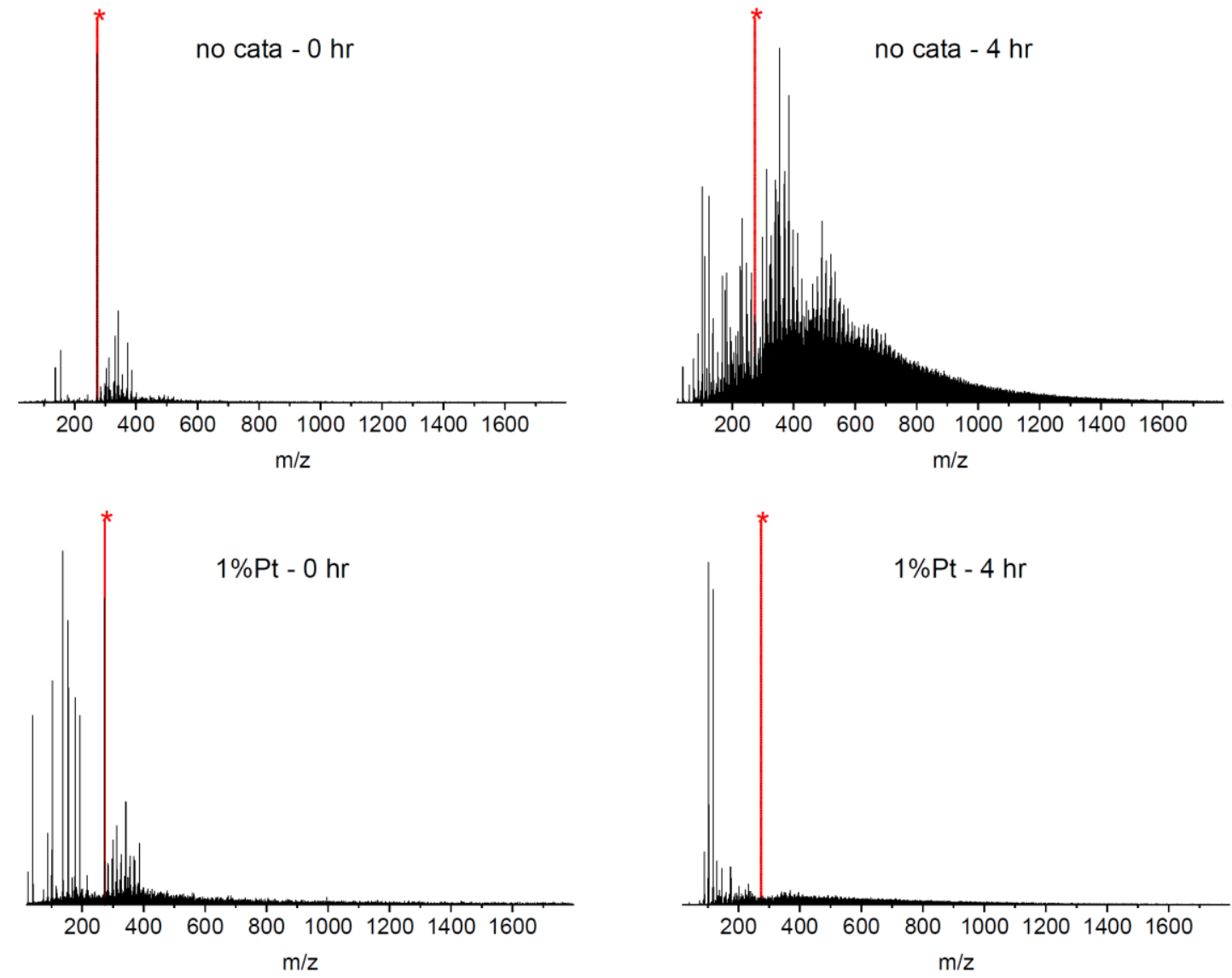

Figure 4. MALDI-TOF spectra of lignin oils, at initial time $\left(0 \mathrm{~h}\right.$ at $\left.250^{\circ} \mathrm{C}\right)$ and 4 hours for both catalytic and non-catalytic reactions ( $*$ is at $\mathrm{m} / \mathrm{z} 273$, the peak of DHB matrix).

The MALDI-TOFMS spectra for the other reaction time and for the raw lignin are presented in Supplementary Material.

Soda lignin presents only a weak ionization and featuring mainly peaks of about $400 \mathrm{Da}$, regardless of ionization optimization attempts (supplementary material). It was not possible under our conditions to analyze the molecular weight of lignin by MALDI-TOF MS. This finding is consistent with previous work. [55] Indeed, $\mathrm{m} / \mathrm{z}$ higher than 2000 are poorly resolved in previous work on MALDI-TOF analysis of lignin. MALDI is rather used for lignomic analysis of oligomers ${ }^{[57,58]}$ with higher resolution mass spectrometers (resolution in the range of 200000) than for TOFMS.

DHB has been shown as a good matrix for the detection of oxygen moieties in lignin oligomers. ${ }^{[5]}$ For this reason, we have selected this matrix and optimized ionization conditions on lignin-oil analysis. 
Figure 4 shows that a weak signal was detected between $\mathrm{m} / \mathrm{z} 300$ and 400 for the uncatalyzed experiment on the initial sampling $\left(0 \mathrm{~h}\right.$ at $\left.250^{\circ} \mathrm{C}\right)$. After $2 \mathrm{~h}$, a bimodal distribution is detected, composed of a primary ion pool from $\mathrm{m} / \mathrm{z} 100-250$ and secondary pool of $250+$. The signal reveals ions up to $1200 \mathrm{Da}$. The catalyzed experiments present a very different behavior. First (at $0 \mathrm{~h}$ ) a bimodal distribution is observed with ions detected between 100 to $200 \mathrm{Da}$ (monomers) and 300 to 400Da (dimers). From 2 hours time on stream, the MALDI signal exhibits mainly a unimodal distribution centered on monomers (100-200 Da).

In order to better compare MALDI-TOFMS analysis with other methods, the sum of ion intensities was determined for 2 groups: 1) from 0 to $240 \mathrm{Da}$ (the biggest molecule quantified by GC/MS) and 2) for ions bigger than 240 (up to $1800 \mathrm{Da}$ ). Figure 5 displays the total ion current (TIC) for these 2 groups.
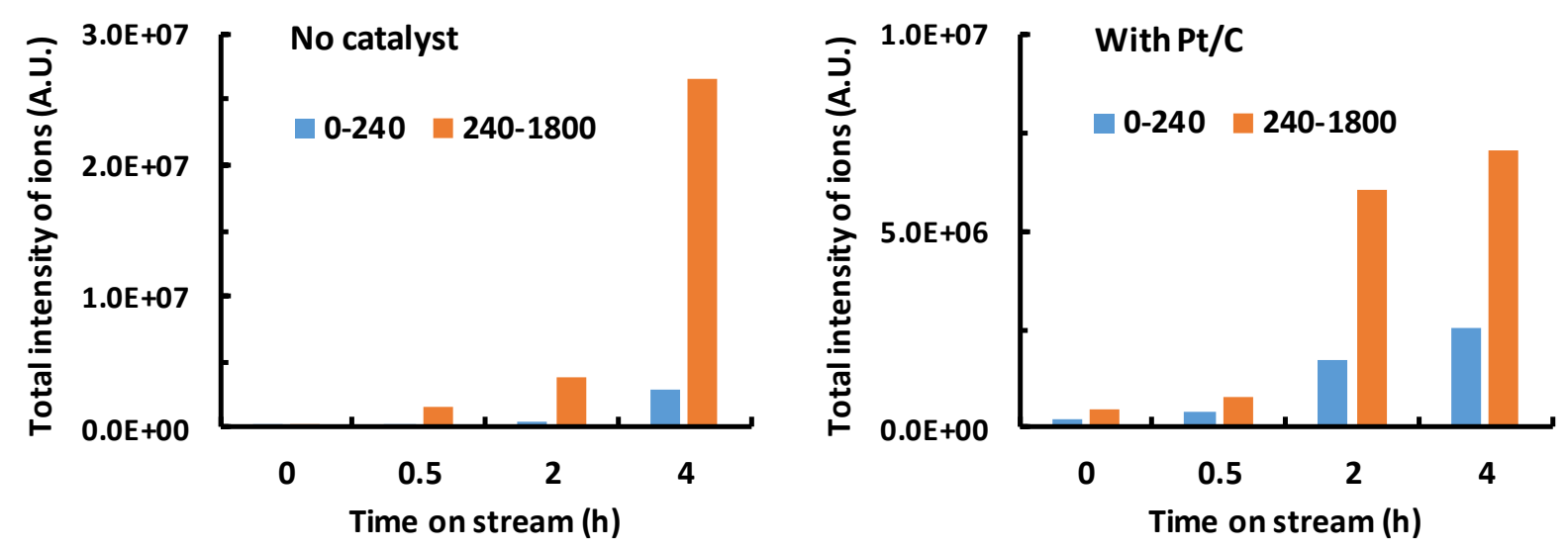

Figure 5. Integration of the signal of ions detected by MALDI-TOFMS in lignin oils from 0 to 240Da and 240 to $1800 \mathrm{Da}$ as a function of reaction time, without and with catalyst

Figure 5 shows that more low molecular weight ions $(<240)$ are detected with $\mathrm{Pt} / \mathrm{C}$ catalyst. An important signal in the range of 240-1800Da appears from 2 hours time on stream for both conditions (with and without catalyst). This signal may result from the concurrent depolymerization of lignin forming monomers and oligomers in competition with condensation reactions. This integration of all $\mathrm{m} / \mathrm{z}$ peaks does not depict the high intensities of some major peaks for $\mathrm{Pt} / \mathrm{C}$ experiments (with $\mathrm{m} / \mathrm{z}$ lower than 200), which is overwritten by the sum of numerous ions with a small individual intensity.

$\mathrm{Mw}$ and Mn were also derived from MALDI-MS signals (figure 6).[55]

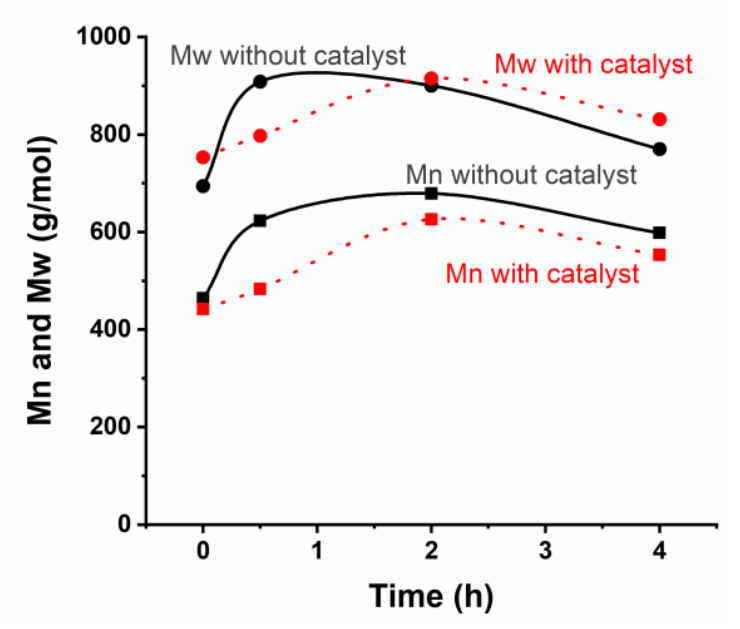

Figure 6. Molecular weight distribution (Mw and Mn) of lignin oils obtained by MALDI-TOFMS as a function of time on stream $\left(\right.$ at $\left.250^{\circ} \mathrm{C}\right)$, with and without catalyst $(\mathrm{Pt} / \mathrm{C})$. 
Mw and Mn of lignin oils obtained by MALDI are relatively stable across reaction sampling times and similar for both conditions (with and without catalysts, see figure 6). This relative stability is consistent with GPC analysis. However, the Mw determined by MALDI are higher (800-900 Da) than those determined by GPC (400-500 Da). The PDI is similar to GPC analysis ( $\sim 1.5 \mathrm{for} \mathrm{Pt} / \mathrm{C}$ experiment). It is possible to notice a slight increase in $\mathrm{Mw}$ after 30min of liquefaction followed by a small decrease until $4 \mathrm{~h}$. This feature may be assigned to secondary condensation reactions followed by a slow conversion of condensed oligomers.

\subsection{Analysis of lignin products by UV spectroscopy}

\subsubsection{UV spectroscopy of model compounds, lignin and isolated oligomers}

UV spectroscopy was initially carried out on nine complementary model compounds: phenol, guaiacol, syringol, catechol, iso-eugenol, 1-naphthol, sinapyl alcohol, coniferyl alcohol and guaiacyglycerol- $\beta$-guaiacyl ether, miming a $\beta$-O-4 dimer. They were chosen for their various side chains as good surrogates of lignin moieties.

First, the UV absorption of these model compounds was studied as well as the absorption of lignin and isolated oligomers. Oligomers were isolated from a lignin liquefaction test without catalyst (after $4 \mathrm{~h}$ ) based on the method of Huang et al. ${ }^{[32]}$ The results are presented in supplementary material.

Lignin, its monomers and oligomers present specific absorption spectra due to the presence of different chromophores as aromatic rings, alkenes and oxygenated chemical groups (ether, carbonyl or hydroxyl) [75,86,96], which may be conjugated. These chromophores are also fluorophores according to the high electronic density of conjugated systems including aromatic rings.

The UV absorption spectra present mainly two absorption bands (for all analyzed compounds): 1) a first one at $\sim 210 \mathrm{~nm}$ corresponding to a $\pi \rightarrow \pi^{*}$ transition in the aromatic ring and 2) a second one at $\sim 275 \mathrm{~nm}$ associated to free and etherified hydroxyl groups, involving a lone pair of one of the oxygen atoms ${ }^{[67]}$.

In lignin and model compounds the $210-220 \mathrm{~nm}$ absorption wavelength can be attributed to the methoxylated phenol ring. It was also shown that free and etherified hydroxyl groups contribute significantly to the characteristic absorption maximum around $280 \mathrm{~nm} .{ }^{[67,97]}$ Lignin and oligomer absorption present a broader absorption peak than model compounds due to the higher complexity in different chemical moieties. For this reason, UV absorption does not show high selectivity for discrimination of the chemical composition of lignin products, and therefore, UV fluorescence has been studied.[67]

All the studied compounds absorb at $275 \mathrm{~nm}$, so they were excited at $275 \mathrm{~nm}$ to record the fluorescence spectra (see supplementary material).

UV fluorescence shows important different peak maxima and intensity depending on the functional groups present in the model compounds. This is in agreement with previous reports that indicate considerable sensitivity of UV fluorescence spectroscopy to the degree of substitution at adjacent positions on the ring, especially when such substitution involves a series of electronegative groups. ${ }^{775,98]}$

Quantum yields were determined based on these fluorescence spectra excited at $275 \mathrm{~nm}$ following the recommendations of IUPAC with quinine sulfate as reference[99]. Quantum yields are presented in the supporting material. They are higher than $20 \%$ for some monomers (such as phenol, guaiacol, eugenol) demonstrating the very high sensitivity of UV fluorescence for our compounds. The quantum yield depends on functional groups present on the aromatic ring. For instance, it decreases significantly for syringol (compared to phenol and guaiacol). Substitutions with electron donating groups like $-\mathrm{OH}$ or $-\mathrm{OR}$ induces a red shift in both absorption and fluorescence spectra. Nevertheless, the presence of lone pairs of electrons on the oxygen 
atoms does not change the nature of the $\pi-\pi^{*}$ transitions of the aromatic system because these lone pairs are directly involved in $\pi$ bonding in the molecule. [100] If methoxy groups are twisted out of the plane of the aromatic ring, for steric hindrance reasons, the degree of conjugation of the system is decreased. Hydroxyl groups are nearly coplanar. ${ }^{[100]}$ The distortions in coplanarity increase as the number of methoxy groups increases from zero (phenol, H) to one (guaiacol, G) to two (syringol, S). This mechanism explains the decreased fluorescence quantum yield of $\mathrm{S}$ compared to $\mathrm{H}$ and $\mathrm{G} .{ }^{[98]}$

The low quantum yield of vanillin can be explained by the aldehyde group which leads to a $\mathrm{n} \rightarrow \pi^{*}$ transition of low energy. ${ }^{[75]}$

Eugenol and naphthol exhibit a high quantum yield due to the high number of $\mathrm{C}=\mathrm{C}$ bonds in the side chain and/or of the aromatic ring. The model dimer (guaiacylglycerol-beta-guaiacyl ether-GGGE) also presents a high quantum yield due to its 2 aromatic rings.

After 1) absorption, and 2) fluorescence at a constant excitation ( $275 \mathrm{~nm})$, we have studied 3) the synchronous fluorescence of our molecules. In synchronous fluorescence spectrometry (SFL), excitation and emission wavelengths vary simultaneously separated by a constant offset. Compared to conventional fluorescence at fixed wavelength, SFL shows much higher spectral resolution for complex mixtures by selecting the appropriate excitation/emission offset according to the molecular structure of the analytes. $[68,70,79,80]$

Figure 7 presents the synchronous spectra for the model compounds, lignin and isolated oligomers. 

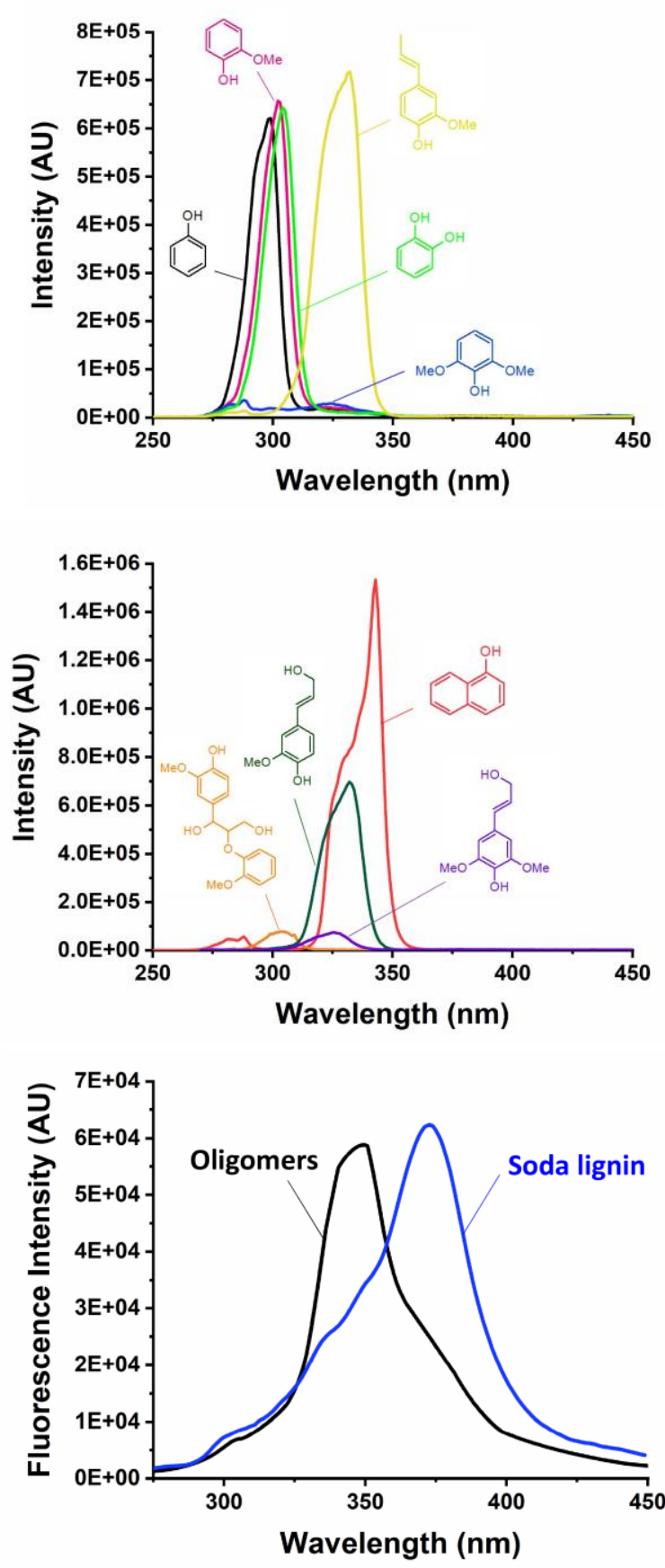

Figure 7. Synchronous UV fluorescence with $20 \mathrm{~nm}$ offset of model compounds, lignin and oligomers (diluted in ethanol)

It is well known that the emission peak in SFL is related to the number of undisrupted conjugated bonds in molecules. For instance, for aromatic hydrocarbons (like PAH), SFL peaks are related to the molecular weight of the molecules. ${ }^{[70,79,80]}$ To the best our knowledge, we present here the first rationale on the synchronous emission on lignin surrogates.

The offset between excitation and fluorescence analysis $(20 \mathrm{~nm})$ has been selected based on previous work. ${ }^{[69,79]}$ This offset has shown an excellent selectivity to discriminate aromatic molecules in complex liquids.

Figure 7 shows that aromatic monomers with hydroxyl and methoxyl groups emit at about $305 \mathrm{~nm}$ (phenol, guaiacol, catechol). Aromatic monomers with propyl side chains (like iso-eugenol, coniferyl alcohol, sinapyl alcohol) emit at about $330 \mathrm{~nm}$. This finding is consistent with the known fundamentals of fluorescence. 
Conjugated molecules present an alternation of simple and double bonds where the $\pi$ electron cloud is delocalized. The presence of two free pairs of electrons on the oxygen atom contributes to this $\pi$ electron cloud delocalization. The increase in the number of conjugated bonds leads to a decrease of the energy between $\pi$ and $\pi^{*}$. Consequently a red shift (bathochromic) is observed in absorption and emission spectra ${ }^{[101-103]}$. On the contrary, smaller and less conjugated structures lead to a blue shift (hypsochromic) of absorption and emission spectra ${ }^{[101]}$.

Naphthol is more conjugated molecule than phenol and therefore it emits at $343 \mathrm{~nm}$ (vs. $300 \mathrm{~nm}$ for phenol). GGGE emits at $305 \mathrm{~nm}$, in a similar range as aromatic monomers (like guaiacol). This fact can easily be explained: the two aromatic rings in GGGE are connected with a $\beta-O-4$ bond which interrupts the conjugation of the molecule. If the conjugation is interrupted and the electron $\pi$ cloud is not in resonance, then the spectra are not redshifted as expected for conjugated molecules (as example for naphthol). Instead, the absorption and fluorescence spectra appear as the ones of a monomeric compound. However, an oxygen linkage between two conjugated moieties does not interrupt the fluorescence due to the 2 lone pairs of electron of the oxygen. ${ }^{100]}$ Consequently, bonds like 4-O-5 or $\mathrm{C}_{\text {arom- }} \mathrm{O}-\mathrm{C}_{\text {arom }}$ in lignin do not interrupt the conjugation of the aromatic rings.

The synchronous fluorescence of lignin is presented on figure 7. To the best of our knowledge, we present for the first time a UV synchronous analysis of lignin with a $20 \mathrm{~nm}$ offset.

Lignin can present conjugated ether bonds (like 4-O-5, $\mathrm{C}_{\text {arom- }}-\mathrm{O}-\mathrm{C}_{\text {arom }}$ ), unconjugated ether bonds (like $\beta$-O-4) and conjugated bonds $\left(\mathrm{C}_{\text {arom }}-\mathrm{C}_{\text {arom }}, \mathrm{C}=\mathrm{C}\right)$. Fluorescent emission of lignins is attributed to conjugated carbonyl, biphenyl, phenylcoumarone and stilbene groups. ${ }^{[75,97]}$ The broad nature of the fluorescence spectra is due to the presence of many different fluorophoric species present in the lignin macromolecule. ${ }^{[75,97]}$

In the raw Soda lignin used in this work, the unconjugated bonds (like $\beta$-O-4) are very low (see NMR analysis in Supplementary Material). Up to $90 \%$ of aromatic rings are linked by $\mathrm{C}-\mathrm{C}$ bonds (and not by ether bonds). This feature explains the red shifted signal of lignin at about $375 \mathrm{~nm}$ (see figure 7). Based on our GPC analysis of this lignin $(\mathrm{Mw} \sim 3500 \mathrm{Da}$ ), this peak at $375 \mathrm{~nm}$ may correspond to the fluorescence of about 20 aromatic units which are connected without important disruption of the conjugation.

The oligomers isolated from the ethanol solution after lignin liquefaction (after $4 \mathrm{~h}$ at $250^{\circ} \mathrm{C}$ ) were also analysed by UV fluorescence (see figure 7). NMR analysis has revealed a complete conversion of the few ether bonds initially present in lignin. Oligomers exhibit a peak maximum at $350 \mathrm{~nm}$, which are blue shifted compared to lignin $(375 \mathrm{~nm})$ due to their lower molecular weight. The high conjugation nature of oligomers and lignin as analyzed by NMR is consistent with our UV fluorescence analysis. Indeed, peaks at $350 \mathrm{~nm}$ and $375 \mathrm{~nm}$ present a bathochromic (red) shift compared to the monomers (at about 300-320nm). GPC analysis of oligomers showed a Mw of about $800 \mathrm{Da}$. The oligomers (fluorescence peak at about $350 \mathrm{~nm}$ ) may correspond to aromatic clusters in a range of 4-6 aromatic rings.

Figure 8 summarizes the emission peak maxima for model lignin compounds, lignin and oligomers for a synchronous excitation with $20 \mathrm{~nm}$ offset. 


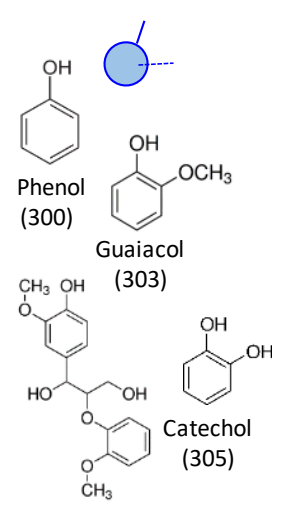

GGGE (304)

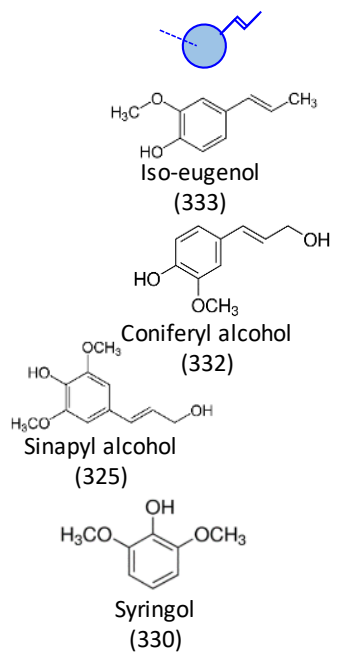

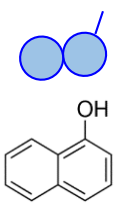

Naphthol-1

(343)

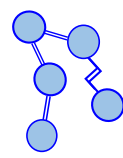

Oligomers

(350)

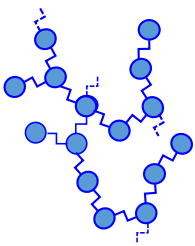

Lignin

(and

lignin residue)

(375)

Emission peak maxima ( $\mathrm{nm})$

Figure 8. Emission peak maxima in synchronous excitation fluorescence (20 nm offset) for model compounds, oligomers and lignin, diluted in ethanol.

\subsubsection{UV fluorescence of lignin liquefaction products}

Based on analysis of model compounds and lignin, we have studied the UV fluorescence of liquefaction products. The goal was to depict important differences between catalytic and non-catalytic experiments based on UV fluorescence. The results of the synchronous fluorescence spectra (20nm offset) are plotted for the different reaction times in figure 9.
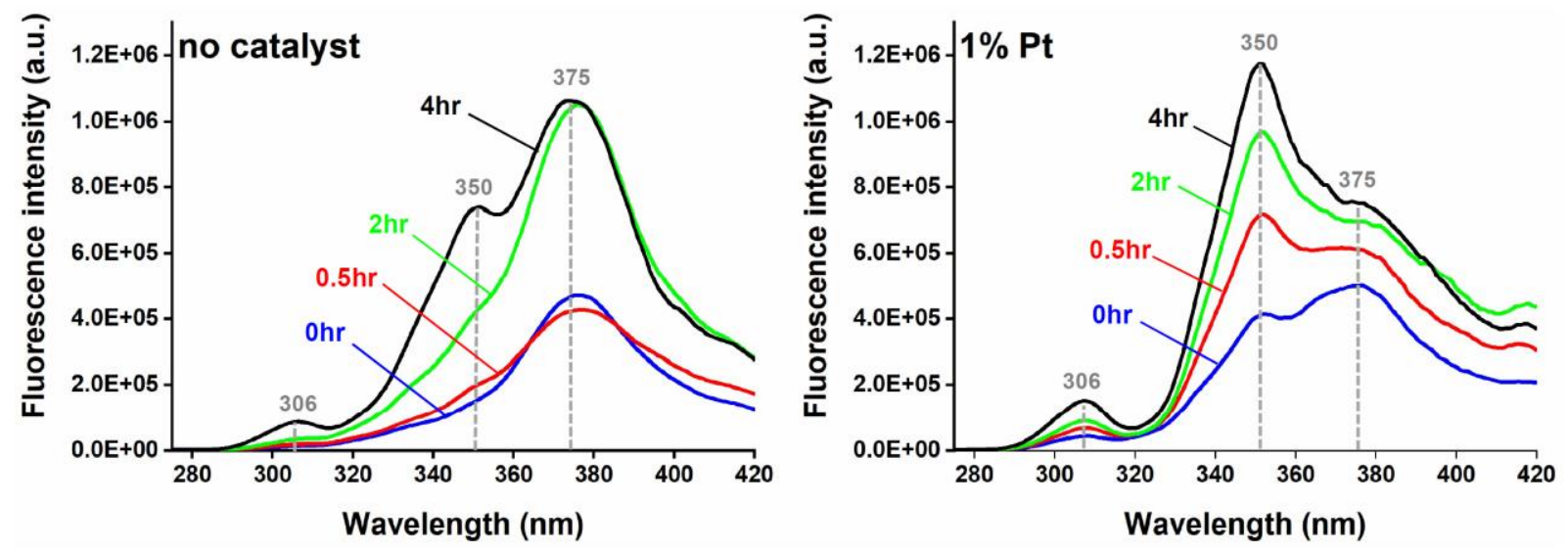

Figure 9. Synchronous Fluorescence (offset 20nm) for different reaction time: a) without catalyst b) synchronous fluorescence with catalyst.

All the spectra from liquefaction products display three main peaks (or shoulder) at 306, 350 and $375 \mathrm{~nm}$, with and without catalyst. These 3 peaks are consistent with the previous section. The first peak can be assigned to monomers, mainly to (alkyl) phenols and guaiacols in agreement with the UV signals of model compounds and with the GC/MS analysis. The following peak (or shoulder) at 350nm can be assigned to oligomers and the last 
peak at $375 \mathrm{~nm}$ to the heavy "lignin residue". This last peak at $375 \mathrm{~nm}$ accounts for big conjugated clusters derived from lignin conversion ("lignin residues") which are still soluble in ethanol.

The monomers $(306 \mathrm{~nm})$, oligomers $(350 \mathrm{~nm})$ and lignin-residues $(375 \mathrm{~nm})$ peaks increase as function of time for both conditions displaying the depolymerization of lignin. The intensity of monomer and oligomer peaks is higher for catalytic conditions (figure 9). The spectra from non-catalytic conditions remain primarily made up by the heavy fraction. The $\mathrm{Pt} / \mathrm{C}$ catalyst presents an important impact on the depolymerization of lignin based on UV fluorescence.

We have conducted a deconvolution in order to better interpret the UV spectra. Curve deconvolution was carried out using Origin software (Originlab, Northampton, MA, USA) with Gaussian peaks. Peaks were deconvoluted at fixed wavelengths of 306, 350 and $375 \mathrm{~nm}$ in line with our discussion. An example of specific deconvolution curve is given in supplementary material.

The deconvolution allows the determination of indicators for assessing lignin depolymerization. We propose the following indexes as:

$$
\begin{aligned}
& D I=\frac{A_{306}+A_{350}}{A_{306}+A_{350}+A_{375}} \\
& M P I=\frac{A_{306}}{A_{306}+A_{350}+A_{375}}
\end{aligned}
$$

Where:

DI is depolymerization index which describes the relative distribution between depolymerized products (monomers and oligomers at 306 and 350nm respectively) and the total area of the UV spectra;

$\mathrm{MPI}_{\text {fluo }}$ is a monomer products index, which assess for the relative distribution in monomers;

$\mathrm{A}_{306}$ is the area of the deconvoluted peak at $306 \mathrm{~nm}$;

$\mathrm{A}_{350}$ is the area of the deconvoluted peak at $350 \mathrm{~nm}$;

$\mathrm{A}_{375}$ is the area of the deconvoluted peak at $375 \mathrm{~nm}$.

These indexes assess semi-quantitatively the relative distribution in monomers (peak at $306 \mathrm{~nm}$ ) and depolymerized products (monomers at $306 \mathrm{~nm}$ and oligomers at $350 \mathrm{~nm}$ ).

A similar approach was proposed by Garcia-Perez on wood bio-oil.[76] It is interesting to note that the GarciaPerez et al. analysis dealt with a different bio-oil, produced from wood fast pyrolysis and not by lignin liquefaction, but it also exhibited 3 main peaks associated to different size of aromatic clusters (mainly from lignin pyrolysis in the wood, in the case of Garcia-Perez et al.). Deconvolution was also proposed on coal liquids but with a higher number of fitting peaks. ${ }^{[68]}$ Here these 3 peaks have been defined as a sufficient number of different sub-groups of products which are supported by our analysis of individual isolated compounds (monomers, oligomers and lignin).

The evolution of these indexes upon the reaction time is given in Figure 10. 


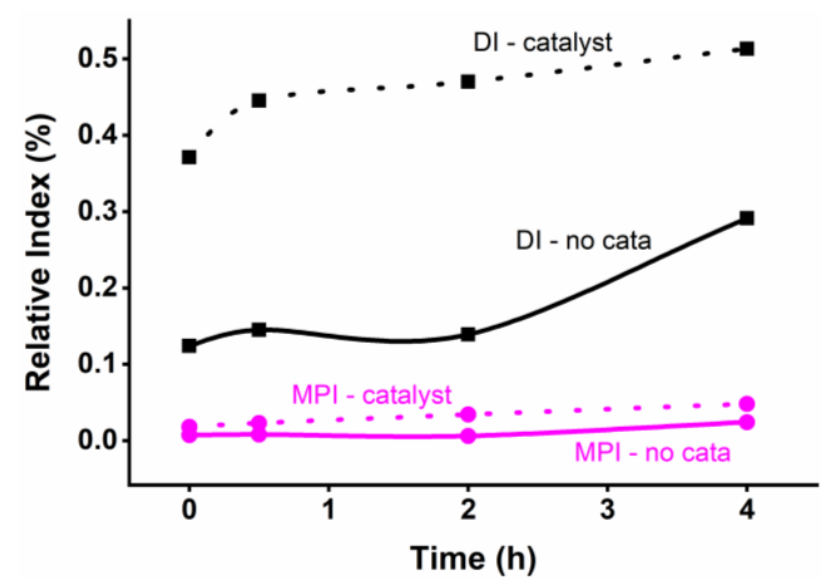

Figure 10. Depolymerization index (DI) and monomeric products index (MPI) obtained by UV fluorescence analysis as a function of liquefaction time $\left(\right.$ at $\left.250^{\circ} \mathrm{C}\right)$, without and with catalyst $(\mathrm{Pt} / \mathrm{C})$

The relative fraction in smaller molecules (DI and MPI) increases with the reaction time. The 2 indexes are higher for the catalytic conditions, most notably for DI. The DI increases much faster (after 0.5hour) and then stays relatively stable for the catalytic conditions. The Pt/C catalyst promotes the formation of oligomers and the conversion of heavy lignin residue. The DI index increases after 2 hours for the uncatalyzed experiment. The MPI index stays relatively small. This analysis reveals that heavy residues are enhanced without catalyst. These soluble heavy residues are probably precursors of solid char. This finding is consistent with the mass of char quantified at the end of the experiment which is much higher for the uncatalyzed experiment (see supplementary material).

These results on UV fluorescence are compared with the other methods in the next section.

\section{Discussion on the complementarity between UV fluorescence and GC/MS, MALDI- TOFMS and GPC analysis}

Figure 11 supports the discussion presented in this section.
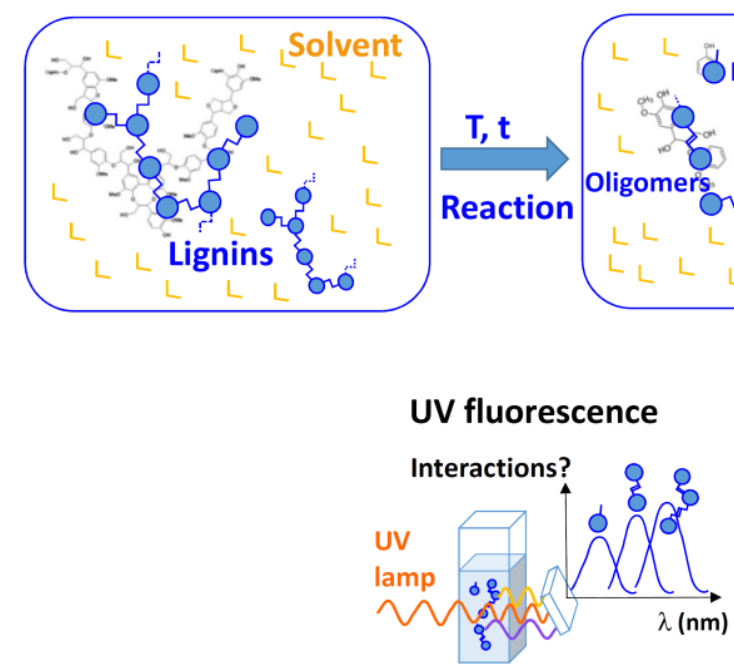

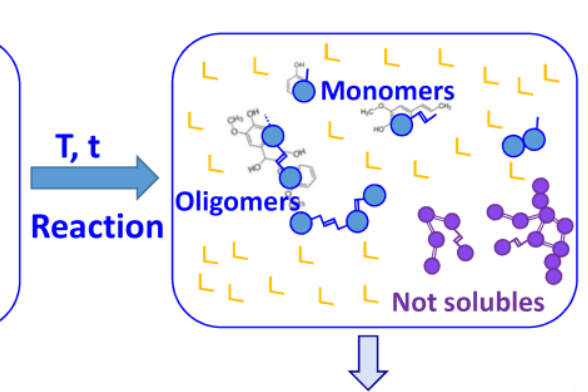

MALDI-TOFMS

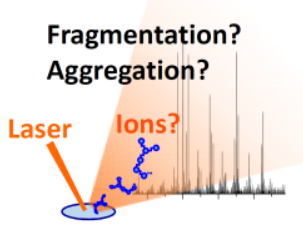

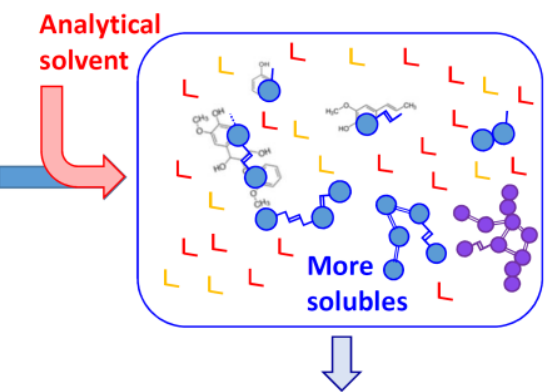

GPC

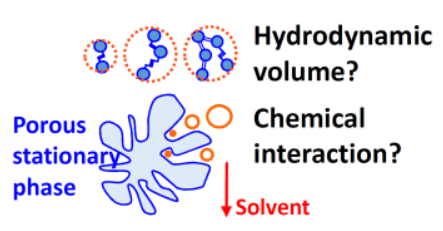

Figure 11. Simplified representation of lignin products in solution and of the analytical methods assessed in this work 
First, lignin is a complex continuum of molecules of various molecular size and chemistry. These macromolecules interact with the solvent (ethanol in our case). Upon liquefaction, they form another continuum of molecules with monomers, oligomers and heavy residues which are partly soluble.

UV fluorescence, MALDI-TOFMS and GC/MS are used directly to analyze this liquid, whereas another solvent (THF) is added for GPC analysis (figure 11). THF may promote the solubility of some big molecules which were in suspension (but not solubilized) in the solution and with a physical dimension smaller than the pores of the filter.

Concerning the average molecular weight of the lignin oil, we have seen differences between GPC and MALDI. This is probably due to calibration issues of the GPC method.[50]

Indeed, GPC separates the molecules based on their hydrodynamic volume in a given solvent (see figure 11). In the case of lignin and its liquefaction products, this volume is different than the standards used for the molecular weight calibration. ${ }^{88,50,51,104]}$ Moreover, chemical interactions with the column phase make GPC potentially an inaccurate technique for determining the molecular weight of lignins and products. ${ }^{[4,50,104,105]}$

Valuable efforts have been undertaken to better calibrate GPC, most notably with synthetized oligomers ${ }^{106]}$ and multi-angle light scattering (MALS) detector. ${ }^{[104]}$ GPC remains as of yet poorly resolved for species smaller than about $1 \mathrm{kDa} .{ }^{[49,50]}$ It does not well tailor for the characterization of oligomers. Other HPLC methods must still be looked into for providing a better separation and quantification of oligomers. ${ }^{[58]}$

Despite the discrepancy between GPC and MALDI, these 2 methods show that the Mw stays relatively stable throughout liquefaction time (figures 3 and 6). This result is also confirmed by the UV fluorescence analysis. Indeed, the peak maxima of the 3 main "families" of products remain at the same wavelength $(306,350$ and $375 \mathrm{~nm}$ ) upon reaction time (see figure 9). Therefore, the average molecular weight of soluble conjugated species does not change significantly during liquefaction.

Based on these 3 techniques, lignin seems to produce quickly an oligomeric pool and then the conversion of oligomers to monomers seems to be slow (a limiting process).

Figure 12 compares the depolymerization index as determined by UV fluorescence plotted against the integrated intensity of all ions detected by MALDI (from $\mathrm{m} / \mathrm{z} 0$ to 1800 , total ion current-TIC).

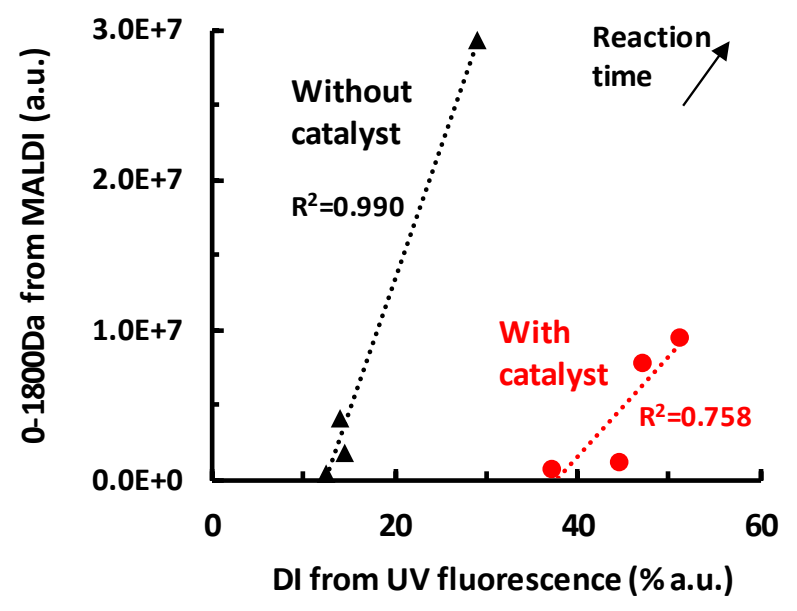

Figure 12. Comparison between the MALDI analysis (integration of all detected ions from $\mathrm{m} / \mathrm{z} 0$ to 1800) and the depolymerization index (DI) derived from UV fluorescence for the 8 lignin oils (without and with catalyst, 4 samples upon liquefaction time) 
The evolution upon reaction time of the total ion current (TIC) (detected by MALDI, up to $\mathrm{m} / \mathrm{z} 1800$ ) is consistent with the evolution of the depolymerization index (DI) determined by UV fluorescence for the experiments without catalyst $\left(\mathrm{R}^{2}=0.99\right.$, see figure 12$)$. The last sampling point (after $4 \mathrm{~h}$ ) produces a very high TIC signal (figure 12) which is not well related to other analyses. The mass spectra presented in figure 4 shows a very broad peaks distribution with a high intensity.

UV fluorescence and MALDI are not well correlated (comparatively) for the catalytic experiment (figure 12, $\mathrm{R}^{2}=0.76$ ). The point after $0.5 \mathrm{~h}$ of catalytic liquefaction presents a low TIC which is not related to other reaction times. The TIC displays all species detected by MALDI whereas the DI accounts only for the relative distribution in monomers and oligomers. A part of heavy residues (not accounted for by the DI) may be detected by MALDI.

This discrepancy can be explained by the different fundamentals of each method (see figure 11).

In MALDI-TOF-MS, the analyte is first mixed with a small organic compound (the matrix) and co-crystallized onto a stainless steel sample holder.[107] The irradiation by a short impulse UV laser leads to the desorption and ionization of the analyte ${ }^{[108-110]}$ (see figure 11). The selectivity and the sensitivity of the analysis depends on the matrix and the laser wavelength with respect to the investigated compound. For all these reasons, MALDI results must be interpreted cautiously. Indeed, fragile molecules may be dissociated (mainly by dehydration or decarboxylation) and aggregation process may occur ( $\pi$-stacking and/or hydrogen bounding) ${ }^{[111]}$. The ions analyzed by MALDI, in our case on lignin liquids, may be enhanced by the fragmentation of heavier species (as "lignin residue"). Indeed, we observed that MALDI TOFMS of raw lignin generated mainly ion signal in low mass range even though MALDI optimization was performed (laser fluence, matrix/sample ratio). In our operating conditions, ion suppression on the end of the $\mathrm{m} / \mathrm{z}$ scale might result from poor ionization efficiency of high MW compounds and from the lack of mass resolution. We have checked the high $\mathrm{m} / \mathrm{z}$ range signals presented in literature. Only unresolved and noisy signals were also detected by previous work on MALDI TOFMS analysis of raw lignin. ${ }^{[12,113]}$ Consequently, common MALDI approaches fail to cover the real mass distribution on the whole broad mass range of lignin and of heavy liquefaction products. ${ }^{[56,57]}$ MALDI or LDI remains an interesting method for oligomer analysis if LDI is combined with high resolution (HR) MS and if careful ionisation conditions are used.[144] (MA)LDI-HRMS can provide the elemental formula of oligomers and even their chemical structure if it is combined with an advanced stochastic modeling approach ${ }^{[57]}$.

The analysis of lighter compounds by MALDI, UV fluorescence and GC/MS is compared in figure 13. 

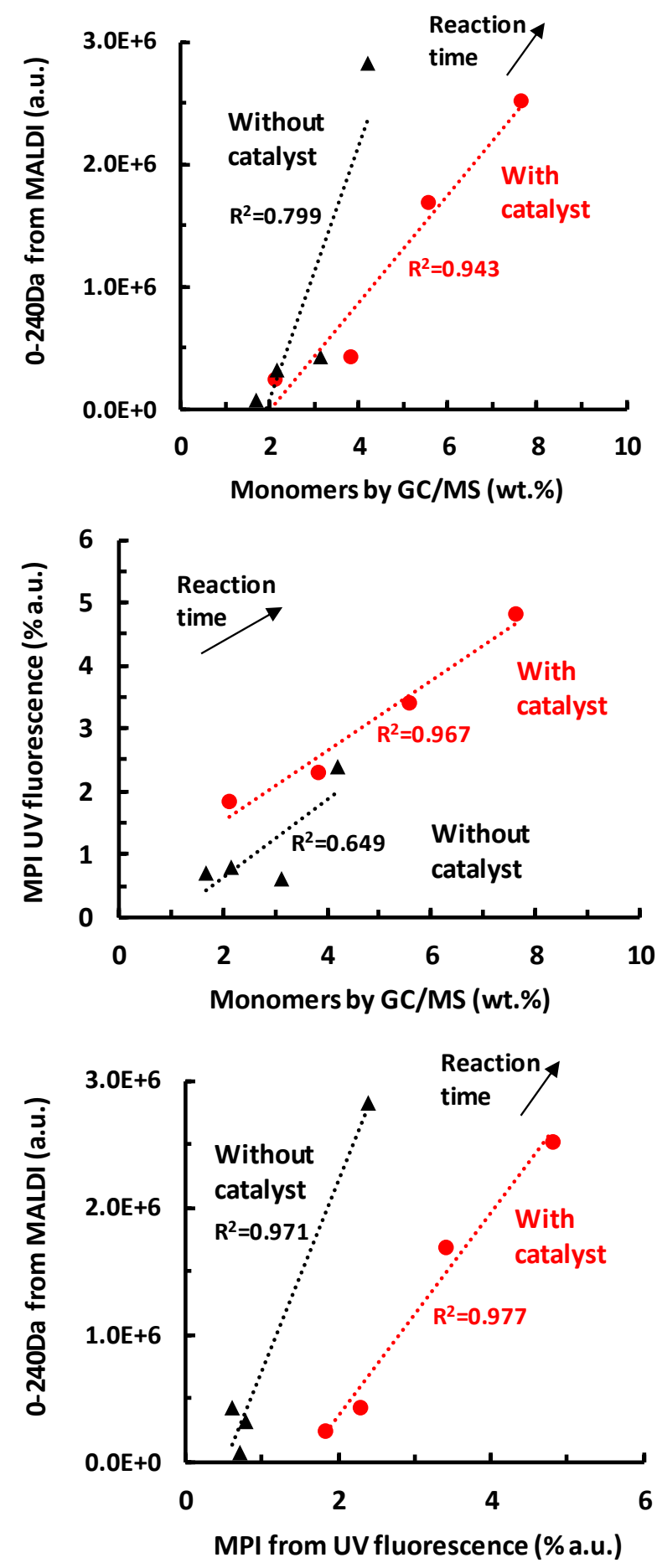

Figure 13. Comparison between low MW species detected by MALDI ( $\mathrm{m} / \mathrm{z}$ 0-240), products quantified by GC/MS (up to 240Da) and the monomers index (MPI) derived from UV fluorescence

A good correlation is presented in figure 13 between MALDI analysis ( $\mathrm{m} / \mathrm{z}$ from 0 to 240), UV fluorescence (monomer index) and GC/MS, especially for the catalytic liquefaction $\left(\mathrm{R}^{2}>0.95\right)$. The point after 2 hours of uncatalyzed liquefaction is not well related to the others.

UV fluorescence is consistent with GC/MS because the major monomers (alkyl phenols) as quantified by GC/MS present a high quantum yield at a fixed emission maximum. Therefore, their signal is well captured by our deconvolution method.

GC/MS-FID is the only technique presented in this work which gives a true quantitative mass yield of light products. It is the technique of choice to quantify light species (lower than about 250Da) and to reveal their 
molecular structure. Nevertheless, attention must be paid to potential oligomers cracking in the GC injector which may produce monomers and therefore overestimate their yields. This fact has been evidenced on cellulose oil analysis. ${ }^{[115]}$

MALDI presents some potential pitfalls (as previously explained) but it matches surprisingly well with UV fluorescence.

Fluorescence is the most direct analytical method with less potential side effects. The sample is simply diluted in ethanol. It is not heated (like in GC/MS or in MALDI), not subjected to a high photon flux (like in MALDI) and/or not diluted in another solvent (like for GPC). UV fluorescence is only based on the intrinsic electronic properties of soluble molecules and of the solvent.

Nevertheless, this technique also presents some pitfalls:

1) It requires conjugated molecules without disruption in their conjugation. If the conjugation is disrupted (like in GGGE with $\beta$-O-4 linkage), the emission is shifted to lower wavelength and the relative content in small molecules can be overestimated.

2) Big macromolecules with numerous chemical moieties present a broader and less resolved emission peak.

3) The quantum yield ("response factor") is a function of the chemical moieties in molecules. Consequently, UV fluorescence is hardly quantitative if complex liquids with numerous chemical moieties are analyzed without prior separation. This is why "relative distribution" is emphasized in this work.

4) The fluorescence of molecules is impacted by the type of solvent used. Solvents can stabilize the excited state of the fluorophore. This effect becomes larger with increasing solvent polarity, resulting in emission at longer wavelengths. ${ }^{[86]}$

5) The fluorescence emission of a component may be absorbed by another component (masking or partial masking of one component by others) ${ }^{[116]}$.

6) Intermolecular energy transfer may occur from an excited aromatic molecule to another aromatic molecule[116]. This energy transfer is minimized under our very dilute solutions studied in this work $(0.2$ absorption at $275 \mathrm{~nm}$ ). Experiments of spiking guaiacol in a naphthol solution demonstrate that no intermolecular energy transfer may occur under our diluted conditions (see supplementary material).

7) Intramolecular energy transfer in a big macromolecule (as oligomers or lignin residues) may also occur from smaller to larger aromatic ring system (in the same macromolecule). This may result in fluorescence emission at longer wavelength and to an overestimation of big aromatic cluster in the macromolecule $[16]$.

Figure 14 presents a simplified mechanism of lignin solvent liquefaction. 


\section{Lignin molecules}

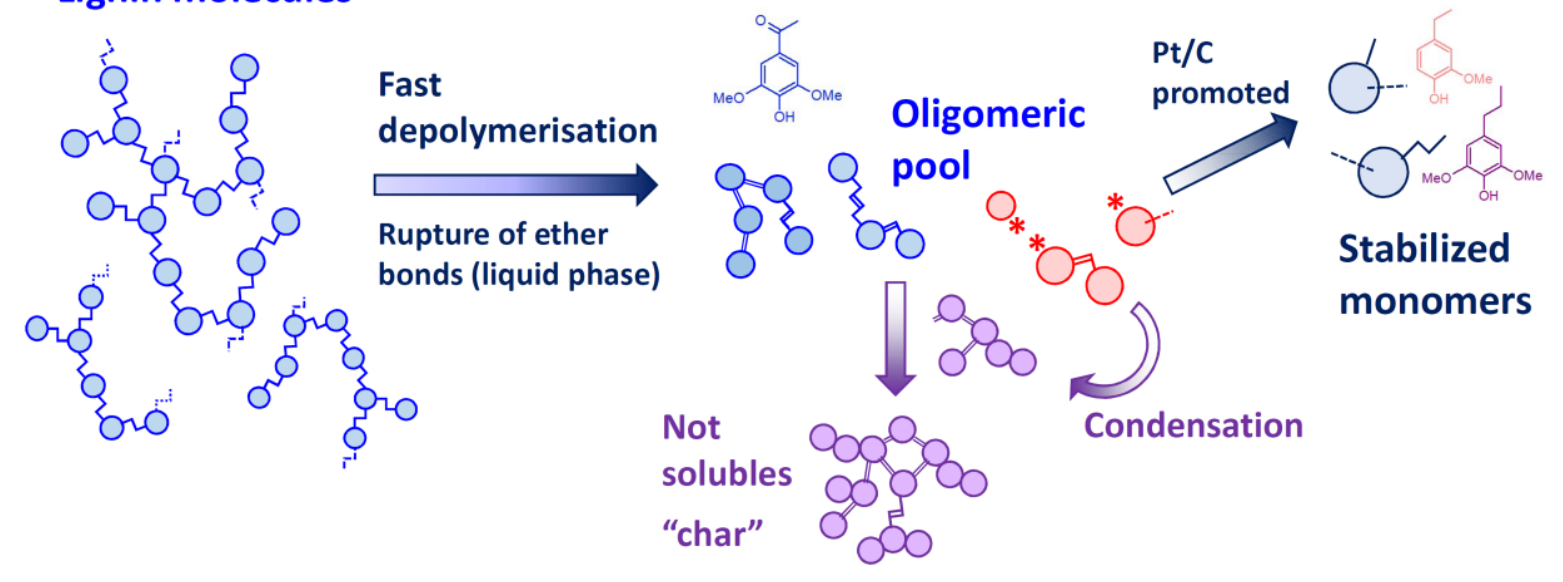

Figure 14. Simplified representation of lignin depolymerization in ethanol based on the complementary methods employed in this work

This mechanism can be proposed thanks to the complementarity of each method:

1) GPC, MALDI and UV fluorescence show that the average molecular weight of lignin oil stays relatively constant throughout liquefaction reaction time. Therefore, there is a competition between depolymerization of oligomers (production of monomers) and condensation reactions (formation of "secondary" oligomers and char). The conversion of oligomers to monomers seems to be the limiting step.

2) GC/MS gives the evolution of monomers throughout liquefaction time. Alkyl phenols are considerably promoted by the $\mathrm{Pt} / \mathrm{C}$ catalyst. $\mathrm{Pt} / \mathrm{C}$ may promote the transfer of $\mathrm{H}$ atoms which stabilize the broken bonds and form more stabilized monomers. The early formation of acetosyringone does not depend on the presence of the catalyst. It confirms the fast depolymerization, in the liquid phase, by the rupture of the few $\beta-\mathrm{O}-4$ bonds present initially in the lignin. This reaction is not promoted by our catalyst.

3) NMR analysis of lignin and oligomers corroborates this finding on the easy conversion of $\beta-\mathrm{O}-4$ bonds. NMR describes the overall composition of lignin and oligomers and reveals their highly conjugated nature.

4) MALDI and UV fluorescence highlight the relative production of monomers and oligomers throughout liquefaction time.

Other methods may be of interest to get a more complete understanding of lignin liquefaction mechanisms, notably:

1) NMR of insoluble species ${ }^{[17]}$;

2) Direct HRMS combined with lignomics-based approach to reveal the chemical structure of oligomers ${ }^{[57]}$

3) LC/MS to quantify oligomers main species;

4) Catalyst characterization.

\section{Conclusion}

In this article we have presented the following results:

1) Surrogates of lignin depolymerization products, lignin and isolated oligomers (produced from liquefaction) have been studied in detail by UV fluorescence.

2) Synchronous fluorescence is the more selective mode for discriminating the molecules based on their molecular weight if the conjugation is not disrupted in the molecule (for instance by a $\beta$-O- 4 bond). 
3) NMR characterization has shown that Soda lignin and oligomers are mainly composed of conjugated moieties. Therefore, UV fluorescence is a relevant method to study this complex lignin oil.

4) A depolymerization index has been derived from UV fluorescence.

5) This index allows for a fast and simple analysis (in less than 15min.) of the relative distribution of monomers and oligomers as a function of liquefaction conditions.

6) UV fluorescence is compared to GC/MS, MALDI-TOFMS and GPC characterization of the same liquid samples.

7) These techniques give complementary information.

8) GPC and MALDI results must be interpreted cautiously and need further development on lignin oligomers.

9) UV fluorescence is the most direct analytical method with fewer potential side effects. It is only based on the intrinsic electronic properties of soluble molecules and of the solvent.

Concerning the perspectives of this work, this approach could be extended to other complex liquids presenting conjugated molecules, in other solvents or from other processes, such as biomass pyrolysis oil or hydrothermal liquefaction oils (etc.). We think that UV spectroscopy has not yet been explored enough for understanding lignin liquids. Many findings can still be instigated based on early studies of fossil fuels, including asphaltenes and coal liquids.

\section{Acknowledgments}

This work has been funded by the French National Agency (ANR) through the PhenoLiq project. We thank Sébastien Leclerc (Université de Lorraine) for the NMR analyses which were performed on the "NMR platform of the Jean Barriol Institute", Université de Lorraine. 


\section{References}

[1] A. J. Ragauskas, G. T. Beckham, M. J. Biddy, R. Chandra, F. Chen, M. F. Davis, B. H. Davison, R. A. Dixon, P. Gilna, M. Keller, P. Langan, A. K. Naskar, J. N. Saddler, T. J. Tschaplinski, G. A. Tuskan, C. E. Wyman, Science 2014, 344, 1246843-1246843.

[2] J. Zakzeski, P. C. A. Bruijnincx, A. L. Jongerius, B. M. Weckhuysen, Chemical Reviews 2010, 110, 35523599 .

[3] J. V. Vermaas, L. D. Dellon, L. J. Broadbelt, G. T. Beckham, M. F. Crowley, ACS Sustainable Chemistry \& Engineering 2019, 7, 3443-3453.

[4] R. Vanholme, B. De Meester, J. Ralph, W. Boerjan, Curr. Opin. Biotechnol. 2019, 56, 230-239.

[5] J. Ralph, C. Lapierre, W. Boerjan, CURRENT OPINION IN BIOTECHNOLOGY 2019, 56, 240-249.

[6] R. Samuel, M. Foston, N. Jiang, L. Allison, A. J. Ragauskas, Polymer Degradation and Stability 2011, 96, 2002 2009.

[7] M. Y. Balakshin, E. A. Capanema, RSC Adv. 2015, 5, 87187-87199.

[8] S. Constant, H. L. J. Wienk, A. E. Frissen, P. de Peinder, R. Boelens, D. S. van Es, R. J. H. Grisel, B. M. Weckhuysen, W. J. J. Huijgen, R. J. A. Gosselink, P. C. A. Bruijnincx, Green Chemistry 2016, 18, 26512665.

[9] E. I. Evstigneyev, S. M. Shevchenko, Wood Science and Technology 2018, 53, DOI 10.1007/s00226-018-10591.

[10] P. C. A. Bruijnincx, R. Rinaldi, B. M. Weckhuysen, Green Chem. 2015, 17, 4860-4861.

[11] Z. Chen, C. Wan, Renewable and Sustainable Energy Reviews 2017, 73, 610-621.

[12] R. J. A. Gosselink, E. de Jong, B. Guran, A. Abächerli, Industrial Crops and Products 2004, 20, 121-129.

[13] S. Laurichesse, L. Avérous, Progress in Polymer Science 2013, 39, DOI 10.1016/j.progpolymsci.2013.11.004.

[14] E. Ten, W. Vermerris, Journal of Applied Polymer Science 2015, 132, DOI 10.1002/app.42069.

[15] R. B. Melati, F. L. Shimizu, G. Oliveira, F. C. Pagnocca, W. de Souza, C. Sant'Anna, M. Brienzo, Bioenerg. Res. 2019, 12, 1-20.

[16] H. Wang, Y. Pu, A. Ragauskas, B. Yang, Bioresource Technology 2019, 271, 449-461.

[17] R. Rinaldi, R. Jastrzebski, M. T. Clough, J. Ralph, M. Kennema, P. C. A. Bruijnincx, B. M. Weckhuysen, Angewandte Chemie International Edition 2016, 55, 8164-8215.

[18] J. Becker, C. Wittmann, Biotechnol. Adv. 2019, DOI 10.1016/j.biotechadv.2019.02.016.

[19] C. E. J. J. Vriamont, T. Chen, C. Romain, P. Corbett, P. Manageracharath, J. Peet, C. M. Conifer, J. P. Hallett, G. J. P. Britovsek, ACS Catalysis 2019, 9, 2345-2354.

[20] C. K. Yamakawa, F. Qin, S. I. Mussatto, Biomass and Bioenergy 2018, 119, 54-60.

[21] X. Liu, Z. Jiang, S. Feng, H. Zhang, J. Li, C. Hu, Fuel 2019, 244, 247-257.

[22] M. V. Galkin, J. S. M. Samec, ChemSusChem 2016, 9, 1544-1558.

[23] T.-Q. Yuan, F. Xu, R.-C. Sun, Journal of Chemical Technology \& Biotechnology 2013, 88, 346-352.

[24] W. Schutyser, T. Renders, S. Van den Bosch, S.-F. Koelewijn, G. T. Beckham, B. F. Sels, Chemical Society Reviews 2018, 47, 852-908.

[25] J. E. Holladay, J. J. Bozell, J. F. White, D. Johnson, DOE Report PNNL 2007, 16983.

[26] J. S. Shabtai, W. W. Zmierczak, E. Chornet, Process for Conversion of Lignin to Reformulated, Partially Oxygenated Gasoline, 2001, US6172272B1.

[27] O. Faix, D. Meier, Holz als Roh-und Werkstoff 1989, 47, 67-72.

[28] C. Chio, M. Sain, W. Qin, Renewable and Sustainable Energy Reviews 2019, 107, 232-249.

[29] C. Amen-Chen, H. Pakdel, C. Roy, Bioresource Technology 2001, 79, 277-299.

[30] J.-Y. Kim, J. Park, U.-J. Kim, J. W. Choi, Energy \& Fuels 2015, 29, 5154-5163.

[31] X. Huang, C. Atay, T. I. Korányi, M. D. Boot, E. J. M. Hensen, ACS Catalysis 2015, 5, 7359-7370.

[32] X. Huang, T. I. Korányi, M. D. Boot, E. J. M. Hensen, Green Chemistry 2015, 17, 4941-4950.

[33] X. Huang, T. I. Korányi, M. D. Boot, E. J. M. Hensen, ChemSusChem 2014, 7, 2276-2288.

[34] X. Huang, C. Atay, J. Zhu, S. W. L. Palstra, T. I. Korányi, M. D. Boot, E. J. M. Hensen, ACS Sustainable Chemistry \& Engineering 2017, 5, 10864-10874.

[35] J. Wildschut, F. H. Mahfud, R. H. Venderbosch, H. J. Heeres, Ind. Eng. Chem. Res. 2009, 48, 10324-10334. 
[36] E. Terrell, L. D. Dellon, A. Dufour, E. Bartolomei, L. J. Broadbelt, M. Garcia-Perez, Industrial \& Engineering Chemistry Research 2020, 59, 526-555.

[37] E. I. Kozliak, A. Kubátová, A. A. Artemyeva, E. Nagel, C. Zhang, R. B. Rajappagowda, A. L. Smirnova, ACS Sustainable Chemistry \& Engineering 2016, 4, 5106-5122.

[38] M. J. Gilkey, B. Xu, ACS Catal. 2016, 6, 1420-1436.

[39] J. Yang, L. Zhao, S. Liu, Y. Wang, L. Dai, Bioresource Technology 2016, 212, 302-310.

[40] F. P. Bouxin, A. McVeigh, F. Tran, N. J. Westwood, M. C. Jarvis, S. D. Jackson, Green Chemistry 2015, 17, 1235-1242.

[41] L. Shuai, M. T. Amiri, Y. M. Questell-Santiago, F. Héroguel, Y. Li, H. Kim, R. Meilan, C. Chapple, J. Ralph, J. S. Luterbacher, Science 2016, 354, 329-333.

[42] R. Shu, J. Long, Z. Yuan, Q. Zhang, T. Wang, C. Wang, L. Ma, Bioresource Technology 2015, 179, 84-90.

[43] K. Barta, T. D. Matson, M. L. Fettig, S. L. Scott, A. V. Iretskii, P. C. Ford, Green Chemistry 2010, 12, 1640.

[44] S. Jeong, S. Yang, D. H. Kim, Molecular Catalysis 2017, 442, 140-146.

[45] D. J. McClelland, A. H. Motagamwala, Y. Li, M. R. Rover, A. M. Wittrig, C. Wu, J. S. Buchanan, R. C. Brown, J. Ralph, J. A. Dumesic, G. W. Huber, Green Chemistry 2017, 19, 1378-1389.

[46] N. Mahmood, Z. Yuan, J. Schmidt, M. Tymchyshyn, C. (Charles) Xu, Green Chem. 2016, 18, 2385-2398.

[47] B. Shrestha, Y. le Brech, T. Ghislain, S. Leclerc, V. Carré, F. Aubriet, S. Hoppe, P. Marchal, S. Pontvianne, N. Brosse, A. Dufour, ACS Sustainable Chemistry \& Engineering 2017, 5, 6940-6949.

[48] M. C. Barnés, M. M. de Visser, G. van Rossum, S. R. A. Kersten, J.-P. Lange, Journal of Analytical and Applied Pyrolysis 2017, 125, 136-143.

[49] A. A. Andrianova, N. A. Yeudakimenka, S. L. Lilak, E. I. Kozliak, A. Ugrinov, M. P. Sibi, A. Kubátová, Journal of Chromatography A 2018, 1534, 101-110.

[50] G. Zinovyev, I. Sulaeva, S. Podzimek, D. Rössner, I. Kilpeläinen, I. Sumerskii, T. Rosenau, A. Potthast, ChemSusChem 2018, 11, 3259-3268.

[51] C. Dong, C. Feng, Q. Liu, D. Shen, R. Xiao, Bioresource Technology 2014, 162, 136-141.

[52] L. Shao, Q. Zhang, T. You, X. Zhang, F. Xu, Bioresource Technology 2018, 264, $238-243$.

[53] M. Verziu, A. Tirsoaga, B. Cojocaru, C. Bucur, B. Tudora, A. Richel, M. Aguedo, A. Samikannu, J. P. Mikkola, Molecular Catalysis 2018, 450, 65-76.

[54] A. Toledano, L. Serrano, J. Labidi, A. Pineda, A. M. Balu, R. Luque, ChemCatChem 2013, 5, 977-985.

[55] A. A. Andrianova, T. DiProspero, C. Geib, I. P. Smoliakova, E. I. Kozliak, A. Kubátová, Journal of The American Society for Mass Spectrometry 2018, 29, 1044-1059.

[56] Y. Qi, D. A. Volmer, Analytical and Bioanalytical Chemistry 2019, 411, 6031-6037.

[57] E. Terrell, V. Carré, A. Dufour, F. Aubriet, Y. Le Brech, M. Garcia-Pérez, ChemSusChem 2020, n/a, DOI 10.1002/cssc.202000239.

[58] Y. Qi, D. A. Volmer, Rapid Communications in Mass Spectrometry 2019, 33, 2-10.

[59] R. Olcese, V. Carré, F. Aubriet, A. Dufour, Energy \& Fuels 2013, 27, 2135-2145.

[60] J. Hertzog, V. Carré, Y. Le Brech, C. L. Mackay, A. Dufour, O. Mašek, F. Aubriet, Analytica Cbimica Acta 2017, 969, 26-34.

[61] F. Aubriet, T. Ghislain, J. Hertzog, A. Sonnette, A. Dufour, G. Mauviel, V. Carré, J. Am. Soc. Mass Spectrom. 2018, 29, 1951-1962.

[62] Q. Liu, P. Li, N. Liu, D. Shen, Polymer Degradation and Stability 2017, 135, 54-60.

[63] X. Erdocia, R. Prado, M. Á. Corcuera, J. Labidi, Biomass and Bioenergy 2014, 66, 379-386.

[64] R. A. Lee, C. Bédard, V. Berberi, R. Beauchet, J.-M. Lavoie, Bioresource Technology 2013, 144, 658-663.

[65] S. Y. Lin, C. W. Dence, Eds., Methods in Lignin Chemistry, Springer-Verlag, Berlin Heidelberg, 1992.

[66] Z. Chen, M. NaderiNasrabadi, J. A. Staser, P. B. Harrington, J. Anal. Test. 2020, 4, 35-44.

[67] A. M. L. Seca, J. A. S. Cavaleiro, F. M. J. Domingues, A. J. D. Silvestre, D. Evtuguin, C. P. Neto, Journal of Agricultural and Food Chemistry 2000, 48, 817-824.

[68] Z. Wang, C. Wei, H. Shui, S. Ren, C. Pan, Z. Wang, H. Li, Z. Lei, Fuel 2012, 98, 67-72.

[69] A. George, T. J. Morgan, P. Alvarez, M. Millan, A. A. Herod, R. Kandiyoti, Fuel 2010, 89, 2953-2970.

[70] T. Katoh, S. Yokoyama, Y. Sanada, Fuel 1980, 59, 845-850.

[71] G. Mille, M. Guiliano, J. Kister, Organic geochemistry 1988, 13, 947-952.

[72] S. Bayrakceken, A. F. Gaines, P. Keating, C. E. Snape, Fuel 2005, 84, 1749-1759. 
[73] S. Badre, C. Carla Goncalves, K. Norinaga, G. Gustavson, Oliver. C. Mullins, Fuel 2006, 85, 1-11.

[74] S. Goncalves, J. Castillo, A. Fernández, J. Hung, Fuel 2004, 83, 1823-1828.

[75] K. Lundquist, B. Josefsson, G. Nyquist, Hol:forschung 1978, 32, 27-32.

[76] M. Garcia-Perez, S. Wang, J. Shen, M. Rhodes, W. J. Lee, C.-Z. Li, Energy \& Fuels 2008, 22, 2022-2032.

[77] M. B. Pecha, E. Terrell, J. I. Montoya, F. Stankovikj, L. J. Broadbelt, F. Chejne, M. Garcia-Perez, Industrial \& Engineering Chemistry Research 2017, 56, 9079-9089.

[78] J. A. Olmstead, D. G. Gray, Journal of Pulp and Paper Science 1997, 23, J571-J581.

[79] J. J. Delpuech, D. Nicole, D. Cagniant, P. Cleon, M. C. Foucheres, D. Dumay, J. P. Aune, A. Genard, Fuel processing technology 1986, 12, 205-241.

[80] M. Zander, M. W. Haenel, Fuel 1990, 69, 1206-1207.

[81] A. A. Herod, Rapid Communications in Mass Spectrometry 2010, 24, 2507-2519.

[82] R. Bayerbach, V. D. Nguyen, U. Schurr, D. Meier, Journal of Analytical and Applied Pyrolysis 2006, 77, 95101.

[83] J.-Y. de Saint Laumer, E. Cicchetti, P. Merle, J. Egger, A. Chaintreau, Analytical Chemistry 2010, 82, 64576462.

[84] J.-Y. Kim, J. Park, H. Hwang, J. K. Kim, I. K. Song, J. W. Choi, Journal of Analytical and Applied Pyrolysis 2015, 113, 99-106.

[85] A. Richel, C. Vanderghem, M. Simon, B. Wathelet, M. Paquot, Analytical Chemistry Insights 2012, 7, ACI.S10799.

[86] J. R. Lakowicz, Principles of Fluorescence Spectroscopy, Springer US, 2006.

[87] B. Scholze, C. Hanser, D. Meier, Journal of Analytical and Applied Pyrolysis 2001, 58-59, 387-400.

[88] J. Zakzeski, B. M. Weckhuysen, ChemSusChem 2011, 4, 369-378.

[89] J. Zakzeski, A. L. Jongerius, P. C. A. Bruijnincx, B. M. Weckhuysen, ChemSusChem 2012, 5, 1602-1609.

[90] T. J. McDonough, IPST Technical Paper Series 1992.

[91] J. Hu, D. Shen, S. Wu, H. Zhang, R. Xiao, Journal of Analytical and Applied Pyrolysis 2014, 106, 118-124.

[92] T. Nakamura, H. Kawamoto, S. Saka, Journal of Wood Chemistry and Technology 2007, 27, 121-133.

[93] X. Besse, Y. Schuurman, N. Guilhaume, Applied Catalysis B: Environmental 2017, 209, 265-272.

[94] H. Li, X. Yuan, G. Zeng, J. Tong, Y. Yan, H. Cao, L. Wang, M. Cheng, J. Zhang, D. Yang, Fuel Processing Technology 2009, 90, 657-663.

[95] J. Y. Kim, S. Oh, H. Hwang, T. S. Cho, I. G. Choi, J. W. Choi, Chemosphere 2013, 93, 1755-1764.

[96] T. A. Taylor, H. H. Patterson, Analytical Chemistry 1987, 59, 2180-2187.

[97] C.-M. Popescu, C. Vasile, M.-C. Popescu, V. I. Popa, B. S. Munteanu, n.d., 27.

[98] J. C. Dean, P. Navotnaya, A. P. Parobek, R. M. Clayton, T. S. Zwier, The Journal of Chemical Physics 2013, 139, 144313.

[99] A. M. Brouwer, Pure and Applied Chemistry 2011, 83, 2213-2228.

[100] B. Valeur, J.-C. Brochon, New Trends in Fluorescence Spectroscopy: Applications to Chemical and Life Sciences, Springer Science \& Business Media, 2012.

[101] F. Rouessac, A. Rouessac, Chemical Analysis: Modern Instrumentation Methods and Techniques, John Wiley \& Sons, 2013.

[102] M. Sauer, J. Hofkens, J. Enderlein, Handbook of Fluorescence Spectroscopy and Imaging: From Ensemble to Single Molecules, John Wiley \& Sons, 2010.

[103] C. M. Pieper, J. Enderlein, Chemical Physics Letters 2011, 516, 1-11.

[104] I. Sulaeva, G. Zinovyev, J.-M. Plankeele, I. Sumerskii, T. Rosenau, A. Potthast, ChemSusChem 2017, 10, 629-635.

[105] A. E. Harman-Ware, J. R. Ferrell, Energy \& Fuels 2018, 32, 8905-8920.

[106] Y. Li, B. Demir, L. M. V. Ramos, M. Chen, J. A. Dumesic, J. Ralph, Green Chem. 2019, 21, 3561-3572.

[107] Michael. Karas, Franz. Hillenkamp, Anal. Chem. 1988, 60, 2299-2301.

[108] P. Bocchini, G. C. Galletti, R. Seraglia, P. Traldi, S. Camarero, A. T. Martinez, Rapid Communications in Mass Spectrometry 1996, 10, 1144-1147.

[109] R. Zenobi, R. Knochenmuss, Mass Spectrometry Reviews 1998, 17, 337-366.

[110] J. O. Metzger, C. Bicke, O. Faix, W. Tuszynski, R. Angermann, M. Karas, K. Strupat, Angewandte Chemie International Edition in English 1992, 31, 762-764. 
[111] F. Aubriet, V. Carré, in Fundamentals and Applications of Fourier Transform Mass Spectrometry (Eds.: B. Kanawati, P. Schmitt-Kopplin), Elsevier, 2019, pp. 281-322.

[112] A. Jacobs, O. Dahlman, Nordic Pulp \& Paper Research Journal 2000, 15, 120-127.

[113] D. S. Kosyakov, N. V. Ul'yanovskii, E. A. Sorokina, N. S. Gorbova, J Anal Chem 2014, 69, 1344-1350.

[114] Y. Qi, P. Fu, S. Li, C. Ma, C. Liu, D. A. Volmer, Science of The Total Environment 2020, 713, 136573.

[115] P. S. Marathe, A. Juan, X. Hu, R. J. M. Westerhof, S. R. A. Kersten, Journal of Analytical and Applied Pyrolysis 2019, 139, 233-238.

[116] J. R. Kershaw, C. Sathe, J. Hayashi, C.-Z. Li, T. Chiba, Energy \& Fuels 2000, 14, 476-482.

[117] Y. Le Brech, J. Raya, L. Delmotte, N. Brosse, R. Gadiou, A. Dufour, Carbon 2016, 108, 165-177. 


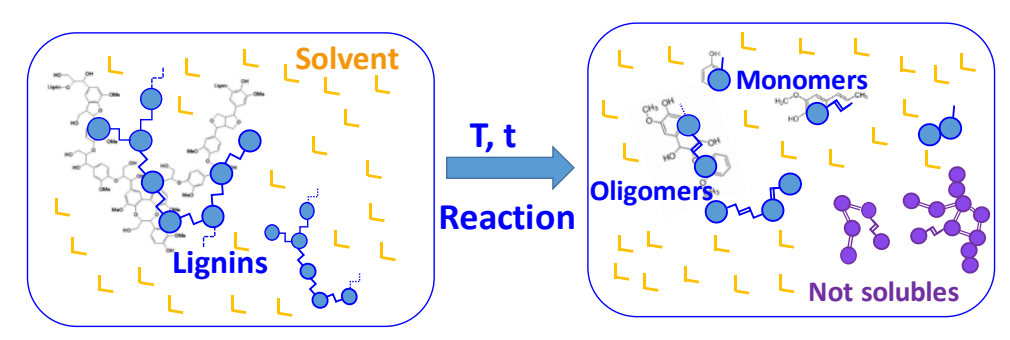

Analysis?

How to analyze liquids produced from lignin? Here we assess different methods to analyse monomers and oligomers. Their pitfalls and benefits are discussed. UV fluorescence is a simple and fast method to analyze the relative distribution between monomers, oligomers and heavier fractions.

Keywords: Lignin, liquefaction, catalysis, oligomers, phenols 